\title{
Sistemas Rígidos Associados a Cadeias de Decaimento Radioativo
}

\author{
Guilherme Galina Loch
}

DISSERTAÇÃO APRESENTADA

$\mathrm{AO}$

Instituto DE MATEMÁtica e EstatísticA

$\mathrm{DA}$

Universidade DE SÃo PAUlo

PARA

OBTENÇÃO DO TÍTULO

DE

Mestre em CiÊnCIAS

Programa: Matemática Aplicada

Orientadora: Profa. Dra. Joyce da Silva Bevilacqua

Durante o desenvolvimento deste trabalho o autor recebeu auxílio financeiro do CNPq

São Paulo, março de 2016 


\section{Sistemas Rígidos Associados a Cadeias de Decaimento Radioativo}

Esta versão da dissertação contém as correções e alterações sugeridas pela Comissão Julgadora durante a defesa da versão original do trabalho, realizada em 05/04/2016. Uma cópia da versão original está disponível no

Instituto de Matemática e Estatística da Universidade de São Paulo.

Comissão Julgadora:

- Prof ${ }^{a}$. Dr ${ }^{\mathrm{a}}$. Joyce da Silva Bevilacqua (orientadora) - IME-USP

- Prof. Dr. Nelson Mugayar Kuhl - IME-USP

- Prof. Dr. Orlando Rodrigues Junior - IPEN-CNEN/SP 


\section{Agradecimentos}

Existem 2 pessoas que merecem um agradecimento especial pelo tanto que contribuíram para esta conquista: Joyce da Silva Bevilacqua e Dilva Maria Galina Loch.

Agradeço primeiramente à Professora Joyce, que me recebeu em São Paulo com muito carinho e tornou-se uma amiga especial, me proporcionando experiências acadêmicas diferenciadas e compreendendo minha ausência e os problemas pessoais que tive durante o processo de escrita deste trabalho. Em nome dela, minha orientadora de mestrado e de vida, agradeço a todos que participaram de maneira significativa da minha caminhada estudantil, desde o ensino básico até a pós-graduação. Professores e colegas com os quais dividi momentos importantes de aprendizado e que foram fundamentais para que eu chegasse até aqui.

Agradeço também à minha fortaleza Dilva, a quem dedico esta conquista. Em nome dela, minha mãe e melhor amiga, agradeço aos meus familiares e amigos, pessoas que tanto amo, por todo o carinho e compreensão que sempre tiveram comigo. É difícil estarmos longe de pessoas especiais, mas o amor supera todas as distâncias e seguidamente me vejo acompanhado em pensamento por todos vocês que estão geograficamente tão distantes de mim. Eu sou muito feliz por vocês existirem. Obrigado por tudo, minha gente! 


\section{Resumo}

\section{LOCH, G. G. Sistemas Rígidos Associados a Cadeias de Decaimento Radioativo.}

2016. 68 f. Dissertação (Mestrado) - Instituto de Matemática e Estatística, Universidade de São Paulo, São Paulo, 2016.

Os progressos computacionais nas últimas décadas e a teoria matemática cada vez mais sólida têm possibilitado a resolução de problemas de alta complexidade, permitindo uma modelagem cada vez mais detalhada da realidade. Tal verdade aplica-se inclusive para os sistemas rígidos de Equações Diferencias Ordinárias (EDOs): existem métodos numéricos altamente performáticos para este tipo de problema, que permitem uma grande variação no tamanho do passo de integração sem impactar na sua convergência. Este trabalho apresenta um estudo sobre o conceito de rigidez e técnicas numéricas para resolução de problemas rígidos de EDOs. O que nos motivou a estudar tais técnicas foram problemas oriundos da Física Nuclear que envolvem cadeias de decaimento radiotativo. Estes problemas podem ser modelados por uma cadeia fechada de compartimentos que se traduz em um sistema de EDOs. Os elementos destas cadeias podem possuir constantes de decaimento com ordens de grandeza muito distintas, caracterizando a sua rigidez e exigindo cautela na resolução das equações que as modelam. Embora seja possível determinar a solução analítica para estes problemas, o uso de métodos numéricos facilita a obtenção da solução quando consideramos sistemas com um número elevado de equações. Além disso, soluções numéricas permitem adaptações na modelagem ou em ajustes de dados com mais facilidade. Métodos implícitos são indicados para a resolução deste tipo de problema, pois possuem uma região de estabilidade ilimitada. Neste trabalho, implementamos dois métodos numéricos que possuem esta característica: o método de Radau II e o método de Rosenbrock. Estes métodos foram utilizados para obtenção de soluções numéricas robustas para problemas rígidos de decaimento radioativo envolvendo cadeias naturais e artificiais, considerando retiradas de elementos das cadeias durante o processo de decaimento e quando queremos determinar qual era o estado inicial de uma cadeia que está em decaimento. Ambos os métodos foram implementados com estratégias de controle do tamanho do passo de integração e produziram resultados consistentes dentro de uma precisão pré-fixada.

Palavras-chave: Equações Diferenciais Ordinárias Rígidas, Cadeias de Decaimento Radioativo, Método de Radau II, Método de Rosenbrock. 


\section{Abstract}

LOCH, G. G. Stiff Systems Associated with Radioactive Decay Chains. 2016. 68 f. Dissertação (Mestrado) - Instituto de Matemática e Estatística, Universidade de São Paulo, São Paulo, 2016.

The computational progress in the last decades and the increasingly solid mathematical theory have made possible the resolution of highly complex problems allowing an ever more detailed modelling of reality. This is true even for the systems of stiff Ordinary Differential Equations (ODEs): there are highly performative numerical methods for this kind of problem which allow a wide variation in the size of integration step without impacting on their convergence. This thesis presents a study about the concept of stiffness and numerical techniques to solve stiff problems of ODEs. What motivated us to study these techniques were problems from the nuclear physics involving radioactive decay chains. These problems could be modelled by a closed chain of compartments which is translated into a system of ODEs. The elements of these chains could have decay constants with very different orders of magnitude which characterizes the stiffness of the problem and requires caution in solving the model equations. Although it is possible to determine the analytical solution to these problems when we consider systems with a high number of equations, calculate the solution by numerical methods becomes easier. Furthermore, numerical solutions allow adaptations in modelling or data adjustments more easily. Implicit methods are indicated to solve this kind of problem because they have a unlimited region of stability. In this study, we implemented two numerical methods which have this feature: Radau II method and Rosenbrock method. These methods were used to obtain robust numerical solutions for stiff problems of radioactive decay involving natural and artificial chains, considering the removal of elements during the decay process and when we want to determine what was the initial state of a chain which is decaying. Both methods were implemented with control strategies for integration step size providing consistent results within a pre-established accuracy.

Keywords: Stiff Ordinary Differential Equations, Radioactive Decay Chains, Radau II Method, Rosenbrock Method. 


\section{Sumário}

$\begin{array}{ll}\text { Lista de Figuras } & \text { ix }\end{array}$

Lista de Tabelas $\quad$ xi

1 Introdução $\quad 1$

1.1 Os Isótopos Radioativos e as Cadeias de Decaimento Radioativo . . . . . . . 1

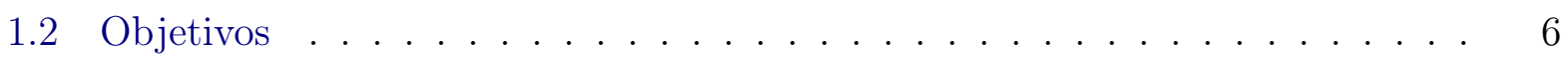

2 Problemas Rígidos de Equações Diferenciais Ordinárias $\quad 7$

2.1 Problemas Rígidos . . . . . . . . . . . . . . . . . 7

3 Soluções para os Problemas Rígidos de Equações Diferenciais Ordinárias 13

3.1 Solução Analítica . . . . . . . . . . . . . . . . . . . . . . . . . 13

3.2 Soluções Numéricas . . . . . . . . . . . . . . . . . . . . . . . . . 14

3.2.1 Métodos de Radau . . . . . . . . . . . . . . . . . . . . . 23

3.2.2 Métodos de Rosenbrock . . . . . . . . . . . . . . . . . . . . 28

4 Simulações Numéricas dos Problemas de Decaimento Radiotaivo 35

4.1 Cadeia Natural de Decaimento do Urânio-238 . . . . . . . . . . . . . . . 35

4.2 Cadeia de Decaimento com Retirada de Elementos . . . . . . . . . . . . . . . 40

4.3 Inventário Passado e Futuro de uma Cadeia de Decaimento . . . . . . . . . . 42

$\begin{array}{lll}5 & \text { Conclusões } & 47\end{array}$

A Métodos de Euler Explícito e Implícito para Resolução de uma Equação $\begin{array}{ll}\text { Rígida } & 49\end{array}$

$\begin{array}{ll}\text { Referências Bibliográficas } & 51\end{array}$ 


\section{Lista de Figuras}

1.1 Cadeia de Decaimento do Molibdênio-99 (Kocher, 1981). . . . . . . . . . . . 3

1.2 Cadeia de Decaimento Natural do Urânio-238 (Kocher, 1981). . . . . . . . . 4

1.3 Série de Decaimento Natural do Urânio-235 (Kocher, 1981). . . . . . . . . . 5

3.1 Região $S_{\alpha}$ (em azul) de $\mathrm{A}(\alpha)$-estabilidade. . . . . . . . . . . . . . . 20

3.2 Região de estabilidade dos Métodos BDF Implícitos (em azul). . . . . . . . . 21

3.3 Região de estabilidade dos Métodos de Adams Implícitos (em azul). . . . . . 21

3.4 Região de estabilidade do Método Radau II de 3 estágios (em azul). . . . . . 25

3.5 Região de estabilidade do Método Rosenbrock de 4 estágios (em azul). . . . . 33

4.1 Solução para Urânio-238. . . . . . . . . . . . . . . . . . . . . . 37

4.2 Solução para Tório-234. . . . . . . . . . . . . . . . . . . . 37

4.3 Solução para Protactínio-234. . . . . . . . . . . . . . . . . . . 38

4.4 Solução para Urânio-234. . . . . . . . . . . . . . . . . . . . . . 38

4.5 Solução para Tório-230. . . . . . . . . . . . . . . . . . . . . . 38

4.6 Solução para Rádio-226. . . . . . . . . . . . . . . . . . . . . . . . . . 38

4.7 Solução para Radônio-222. . . . . . . . . . . . . . . . . . . . . . . 38

4.8 Solução para Polônio-218. . . . . . . . . . . . . . . . . . . . . 38

4.9 Solução para Chumbo-214. . . . . . . . . . . . . . . . . . . . . . . 39

4.10 Solução para Bismuto-214 . . . . . . . . . . . . . . . . . . . . . . . . . . . 39

4.11 Solução para Polônio-214. . . . . . . . . . . . . . . . . . . . . . . . 39

4.12 Solução para Chumbo-210 . . . . . . . . . . . . . . . . . . . . 39

4.13 Solução para Bismuto-210 . . . . . . . . . . . . . . . . . . . . . 39

4.14 Solução para Polônio-210. . . . . . . . . . . . . . . . . . . . . . . 39

4.15 Diferença entre a quantidade de ${ }^{222} \mathrm{Rn}$ em cada um dos casos após 10 bilhões de dias. . . . . . . . . . . . . . . . . . . . . 41

4.16 Inventário da cadeia de decaimento do Molibdênio-99 para o caso em que

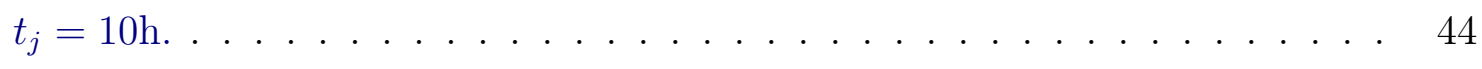

4.17 Cadeia do Molibdênio-99 para $t_{j}=1$ h. . . . . . . . . . . . . 44

4.18 Cadeia do Molibdênio-99 para $t_{j}=10 \mathrm{~h} . \ldots \ldots \ldots$. . . . . . . 44

4.19 Cadeia do Molibdênio-99 para $t_{j}=66 \mathrm{~h} \ldots \ldots \ldots \ldots \ldots$. . . . . 45

4.20 Cadeia do Molibdênio-99 para $t_{j}=100 \mathrm{~h} \ldots \ldots \ldots$. . . . . . 45 
4.21 Abordagem em situação de vazamento/contaminação radioativa. . . . . . . . 46

A.1 Gráfico da Solução Analítica Particular (A.2) . . . . . . . . . . . . . . 50 


\section{Lista de Tabelas}

1.1 Constantes de decaimento da Série de Decaimento Natural do Urânio-235. . . . 5

3.1 Relação entre a ordem $p$ de um método BDF e sua $\mathrm{A}(\alpha)$-estabilidade. . . . . . . . 20

3.2 Matriz de Butcher para o método RK 3.25. . . . . . . . . . . . . . . . . 22

3.3 Matriz de Butcher para o Método Radau II de 3 estágios. . . . . . . . . . . . . . 24

3.4 A-estabilidade do Método Rosenbrock de $s$ estágios e ordem $p$ em função do $\gamma$ escolhido. . . . . . . . . . . . . . . . . . . . . 30

4.1 Meias-vidas e constantes de decaimento da série de decaimento natural do ${ }^{238} \mathrm{U}$ (Kocher, 1981) . . . . . . . . . . . . . . . . . . 36

4.2 Solução após 10 bilhões de dias para a série de decaimento natural do ${ }^{238} \mathrm{U}$. . . . . 37

4.3 Solução após 10 bilhões de dias para a série de decaimento natural do ${ }^{238} \mathrm{U}$ com extração contínua do ${ }^{222} \mathrm{Rn} . \quad$. . . . . . . . . . . . . . . . . . . . . . . 41

4.4 Meias-vidas e constantes de decaimento da série de decaimento do ${ }^{99}$ Mo (Kocher, 1981). . . . . . . . . . . . . . . . . . . . . . . 4 42

4.5 Inventário dos elementos da cadeia do Molibdênio-99 para diferentes valores de $t_{j} .43$

4.6 Inventário da cadeia de decaimento do Molibdênio-99 para o caso em que $t_{j}=10 \mathrm{~h} . \quad 43$

A.1 Desempenho do Método de Euler Explícito para a Equação 2.1. . . . . . . . . . . 50

A.2 Desempenho do Método de Euler Implícito para a Equação 2.1. . . . . . . . . . . 50 


\section{Capítulo 1}

\section{Introdução}

A modelagem matemática é uma ferramenta fundamental para a análise e compreensão de problemas complexos oriundos de diversas áreas do conhecimento e, em muitos casos, é possível representar o problema por meio de um modelo compartimental que se traduz em um sistema linear de Equações Diferenciais Ordinárias. Nestes modelos, cada compartimento está relacionado aos demais por meio de taxas de transferências. Estas taxas de transferência podem apresentar ordens de grandeza muito distintas, de modo que algumas das componentes da solução do sistema decaiam mais rapidamente do que outras, caracterizando a rigidez do problema (Shampine e Gear, 1979), (Lambert, 1991), (Willoughby, 1996), (Deufhard e Bornemann, 2002). Problemas que envolvem séries de decaimento radioativo cujas taxas de decaimento dos elementos variam entre bilhões de anos e frações de segundos configuram alguns exemplos que apresentam rigidez (Thomas e Barber, 1994). Estes fenômenos oriundos da física nuclear serviram como motivação para este estudo. A apresentação destes problemas e os objetivos deste trabalho são detalhados nas próximas sessões deste capítulo.

\subsection{Os Isótopos Radioativos e as Cadeias de Decaimento Radioativo}

O uso de técnicas nucleares baseadas em isótopos radioativos está cada vez mais presente em diversos campos da atividade humana, facilitando a execução de inúmeras tarefas do cotidiano. A indústria, a agricultura e a medicina são algumas das áreas mais beneficiadas (International Atomic Energy Agency, 2004), (Okuno e Yoshimura, 2010).

$\mathrm{Na}$ indústria, uma das aplicações de radioisótopos bastante conhecida é a inspeção de peças metálicas por meio da gamagrafia industrial. Os fabricantes de válvulas usam a gamagrafia na área de controle de qualidade para verificar se há defeitos ou rachaduras no corpo das peças. Usa-se também a gamagrafia para inspecionar a qualidade de soldas, partes de navios e componentes de aviões como motores e asas (Pino e Giovedi, 2005).

$\mathrm{Na}$ agricultura, é possível acompanhar o metabolismo das plantas com a utilização de 
traçadores radioativos. Além disso, a utilização de radioisótopos também é muito útil para o controle e eliminação de pragas. Técnicas nucleares podem ser utilizadas em prol da produção de alimentos e do meio ambiente para determinar a quantidade de um pesticida retido em determinado alimento e a quantidade dele no solo, na água e na atmosfera. Ainda no campo da produção de alimentos, uma aplicação importante é a irradiação de alimentos para sua conservação (da Silva et al., 2009).

Na medicina, milhões de pessoas em todo o mundo são beneficiadas pelo uso de radioisótopos a cada ano, tanto para o diagnóstico como para o tratamento de várias doenças ou disfunções de órgãos e sistemas que compõem o corpo humano. Pode-se citar como exemplo a cintilografia, a radiografia e a radioterapia (de Araújo et al., 2008). Além destes casos, as radiações ionizantes também são utilizados no campo da medicina para esterilização de materiais cirúrgicos (Pino e Giovedi, 2005).

Alguns dos radioisótopos utilizados são naturais e existem na natureza desde a formação do planeta. Outros, por sua vez, são produzidos artificialmente em aceleradores de partículas e reatores nucleares de fissão. Os aceleradores de partículas são máquinas capazes de acelerar feixes de partículas carregadas, fazendo com que estes alcancem velocidades altíssimas, proporcionando energias capazes de produzir matéria em grande quantidade e com o feixe bem controlado. Para a produção de radiofármacos, geralmente são utilizados os aceleradores circulares do tipo cíclotron, que mantêm o feixe segundo uma trajetória curvilínea fazendo com que ele seja acelerado a cada volta. Já os reatores nucleares de fissão utilizam a fissão nuclear para produzir energia (reator de potência) ou para produzir nêutrons (reator de pesquisa). Os nêutrons produzidos pelos reatores nucleares de pesquisa podem ser utilizados para reagir com núcleos alvos, dando origem a outros elementos, que através do processo de decaimento radioativo transformam-se em outros até atingirem a estabilidade nuclear, formando uma cadeia de decaimento radiotaivo. Quando um elemento $x_{1}$ decai para o elemento $x_{2}$, costuma-se chamar $x_{1}$ de elemento pai e $x_{2}$ de elemento filho. Os isótopos radioativos que são utilizados em técnicas nucleares podem ser extraídos das cadeias de decaimento por meio de processos radioquímicos (International Atomic Energy Agency, 2003), (International Atomic Energy Agency, 2009a).

Um exemplo de radioisótopo gerado através do acelerador de partículas do tipo cíclotron é o ${ }^{123}$ I (Iodo-123), que é utilizado em diagnóstico e na monitoração de tratamentos de doenças. No seu processo de produção, alvos estáveis de ${ }^{124}$ Xe (Xenônio-124) são bombardeados com prótons provindos do cíclotron fazendo com que os núcleos fiquem instáveis por excesso de prótons e desintegrem-se até a geração do Iodo-123, que fica absorvido nas paredes do porta alvo. Após a retirada dos demais produtos resultantes das reações e a lavagem do porta alvo com água, o elemento é recolhido (Luiz et al., 2011).

O ${ }^{131}$ I (Iodo-131), que é utilizado em diagnóstico e radioterapia, é produzido por extração a partir dos produtos obtidos da fissão nuclear do ${ }^{235} \mathrm{U}$ ou por bombardeamento com nêutrons no telúrio estável $\left({ }^{130} \mathrm{Te}\right)$ em um reator nuclear. Na produção através do bombardeio do telúrio, o nêutron incide no núcleo do ${ }^{130} \mathrm{Te}$, que se transforma em um isótopo do telúrio, 
que por sua vez se torna o ${ }^{131} \mathrm{I}$.

Outro radioisótopo bastante utilizado na medicina nuclear para o diagnóstico de doenças é o ${ }^{99 m}$ Tc (Tecnécio-99 metaestável), que é produzido a partir do ${ }^{99}$ Mo (Molibdênio-99), conforme mostra a figura 1.1. O Molibdênio-99, por sua vez, pode ser produzido tanto em reatores nucleares a partir da fissão do ${ }^{235} \mathrm{U}$, quanto em cíclotrons, pela ativação do $\mathrm{Zr}$ (Zircônio) (Takahashi, 2004).

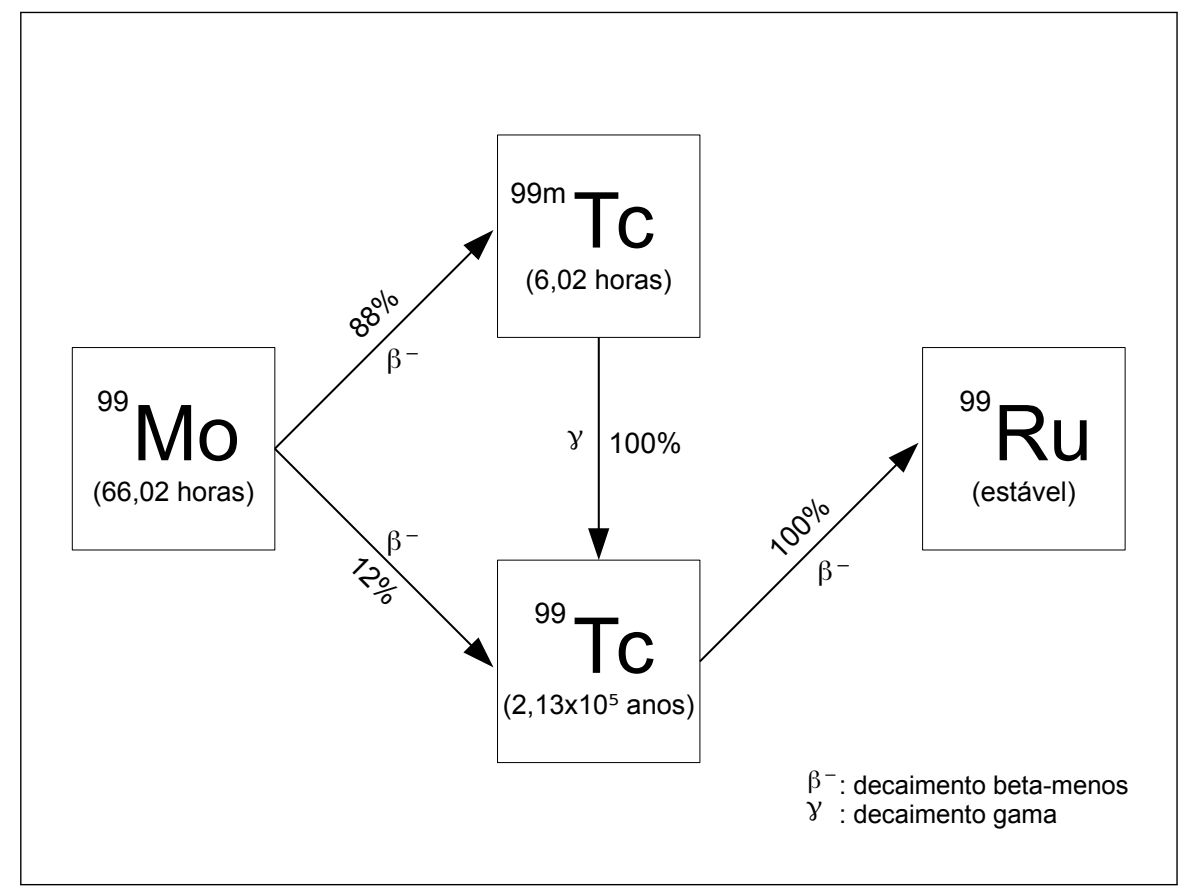

Figura 1.1: Cadeia de Decaimento do Molibdênio-99 (Kocher, 1981).

Independentemente do processo utilizado para geração dos radioisótopos, diferentes tipos e quantidades de rejeitos radiotivos são gerados e é necessário um gerenciamento rigoroso destes rejeitos, uma vez que podem ser altamente radioativos e contaminantes. Desta forma, é importante que se tenha controle sobre a quantidade de cada elemento envolvido nos processos físicos citados anteriormente, de modo que seja possível a geração dos radioisótopos desejados de maneira otimizada e segura (International Atomic Energy Agency, 2009b).

Os processos físicos envolvendo a transmutação de radionuclídeos durante a irradiação de amostras em aceleradores de partículas, na queima de elementos combustíveis em reatores nucleares, ou nas séries de decaimento natural, podem ser representados por modelos matemáticos que descrevem a cadeia de decaimentos radioativos e transformações nucleares. A modelagem matemática compartimental mais simples para uma cadeia de decaimentos radioativos composta por $n$ elementos considera cada um dos elementos como um compartimento interrelacionado aos demais por taxas de transferências e é dada por um sistema linear de Equações Diferenciais Ordinárias (EDOs) de primeira ordem com coeficientes constantes:

$$
x^{\prime}(t)=A x(t)
$$

onde $t \in \mathbb{R}^{+}$é o tempo, $A$ é a matriz $n \times n$ dos coeficientes composta pelas constantes de 
decaimento e as componentes do vetor $x(t) \in \mathbb{R}^{n}$ representam a quantidade de cada elemento da cadeia no instante de tempo $t$.

Se considerarmos uma cadeia de decaimentos composta por $n$ elementos onde cada elemento é representado por um compartimento $x_{i}, i=1, \ldots, n$, e está relacionado aos seus adjacentes por meio de suas constantes de decaimento $\lambda_{i}>0, i=1, \ldots, n$, teremos a matriz $A$ dos coeficientes contendo elementos somente na diagonal e nas posições imediatamente abaixo dela, como é o caso da cadeia de decaimento natural do Urânio-238 (Figura 1.2).

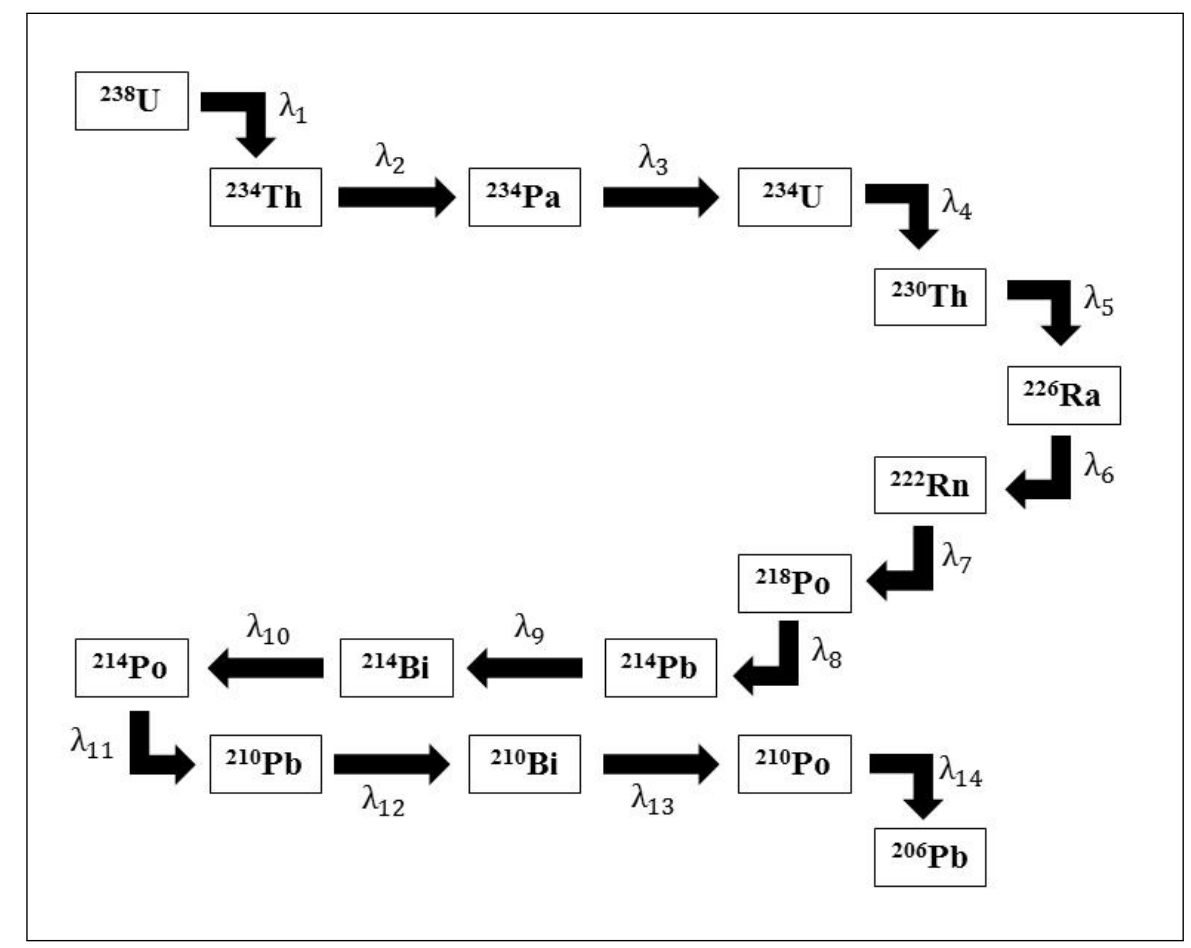

Figura 1.2: Cadeia de Decaimento Natural do Urânio-238 (Kocher, 1981).

As constantes de decaimento $\lambda_{i}, i=1, \ldots, 14$, são calculadas em função das meias-vidas $\left(T_{(1 / 2)}^{i}\right)$ dos elementos da seguinte forma (Kocher, 1981):

$$
\lambda_{i}=\frac{\ln (2)}{T_{(1 / 2)}^{i}} .
$$

Havendo ramificações no modelo e considerando remoção ou inserção de determinada quantidade dos elementos durante o processo de decaimento, a matriz $A$ continua sendo triangular inferior, porém surgem elementos não nulos fora das posições anteriormente citadas. Por exemplo, considere uma parte da série de decaimento natural do Urânio-235, composta pelos sete primeiros elementos da série, conforme apresentado na Figura 1.3.

As constantes de decaimento $\lambda_{i}, i=1, \ldots, 7$, são calculadas em função das meias-vidas $\left(T_{(1 / 2)}^{i}\right)$ apresentadas na Figura 1.3 de acordo com a equação 1.2. Considerando a grande variação das meias-vidas dos elementos envolvidos nessa cadeia, que variam de 21,8 minutos até 703.800 .000 anos, podemos definir o dia como unidade padrão. Dessa forma, a matriz $A$ dos coeficientes para a cadeia composta pelos sete primeiros elementos da série de decaimento 


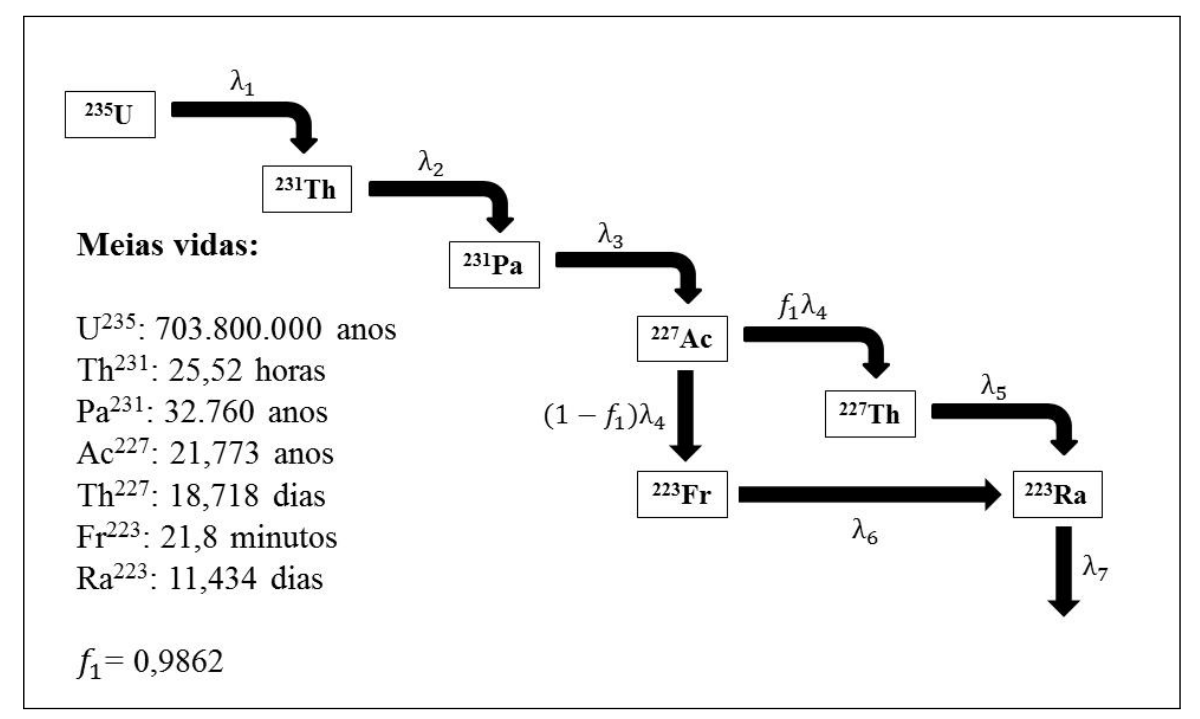

Figura 1.3: Série de Decaimento Natural do Urânio-235 (Kocher, 1981).

natural do Urânio-235 é dada por:

$$
A=\left[\begin{array}{ccccccc}
-\lambda_{1} & 0 & 0 & 0 & 0 & 0 & 0 \\
\lambda_{1} & -\lambda_{2} & 0 & 0 & 0 & 0 & 0 \\
0 & \lambda_{2} & -\lambda_{3} & 0 & 0 & 0 & 0 \\
0 & 0 & \lambda_{3} & -\lambda_{4} & 0 & 0 & 0 \\
0 & 0 & 0 & f_{1} \lambda_{4} & -\lambda_{5} & 0 & 0 \\
0 & 0 & 0 & \left(1-f_{1}\right) \lambda_{4} & 0 & -\lambda_{6} & 0 \\
0 & 0 & 0 & 0 & \lambda_{5} & \lambda_{6} & -\lambda_{7}
\end{array}\right]
$$

A Tabela 1.1 identifica cada radionuclídeo e mostra os valores correspondentes às constantes de decaimento.

\begin{tabular}{lcc}
\hline Elemento & Variável $x_{i}$ & Constante de decaimento $\lambda_{i}\left(\mathrm{dia}^{-1}\right)$ \\
\hline${ }^{235} \mathrm{U}$ & $x_{1}$ & $0,2700 \mathrm{E}-11$ \\
${ }^{231} \mathrm{Th}$ & $x_{2}$ & $0,6518 \mathrm{E}+00$ \\
${ }^{231} \mathrm{~Pa}$ & $x_{3}$ & $0,5796 \mathrm{E}-07$ \\
${ }^{227} \mathrm{Ac}$ & $x_{4}$ & $0,8721 \mathrm{E}-04$ \\
${ }^{227} \mathrm{Th}$ & $x_{5}$ & $0,3703 \mathrm{E}-01$ \\
${ }^{223} \mathrm{Fr}$ & $x_{6}$ & $0,4578 \mathrm{E}+02$ \\
${ }^{223} \mathrm{Ra}$ & $x_{7}$ & $0,6062 \mathrm{E}-01$ \\
\hline
\end{tabular}

Tabela 1.1: Constantes de decaimento da Série de Decaimento Natural do Urânio-235.

Mesmo sendo possível determinar a solução analítica ou semi-analítica para os problemas de decaimento radioativo, soluções numéricas possibilitam, com maior facilidade, adaptações em ajustes de dados ou modelagem. Além disso, para sistemas que modelam cadeias com uma grande quantidade de elementos, o cálculo da solução analítica torna-se demasiadamente 
demorado e trabalhoso, de modo que soluções numéricas tornam-se imperativas.

Porém, é necessária a escolha de métodos numéricos específicos para problemas rígidos, já que é comum haver uma grande diferença nas ordens de magnitude das constantes de decaimento radiotivo dos elementos da cadeia e esta diferença faz com que algumas componentes da solução decaiam mais rapidamente do que outras, o que caracteriza a rigidez do problema (Lambert, 1991), (Stoer e Bulirsh, 1996), (Hairer e Wanner, 1996), (Burden e Faires, 2005), (Semenov, 2011). Observe, por exemplo, na Tabela 1.1, a diferença na ordem de grandeza das constantes de decaimento da série natural do Urânio-235, que variam de $10^{-11}$ até $10^{2}$. Esta diferença implica na rigidez do problema do ${ }^{235} \mathrm{U}$.

As diferenças de magnitude entre as meias-vidas dos elementos de uma cadeia de decaimento radioativo também são consideradas na área da Física Nuclear para determinar o tipo de equilíbrio entre um elemento pai e um elemento filho. Dizemos que os elementos estão em equilíbrio secular quando a meia-vida do radionuclídeo pai $\left(T_{1 / 2}(p)\right)$ é muito maior do que a meia-vida do elemento filho $\left(T_{1 / 2}(d)\right)$, ou seja, $T_{1 / 2}(p)>>T_{1 / 2}(d)$. Quando a meia-vida do pai é maior, mas não muito maior, do que a meia-vida do filho, dizemos que os elementos estão em equilíbrio transiente (Okuno e Yoshimura, 2010).

\subsection{Objetivos}

Este trabalho tem como objetivo principal o estudo de métodos numéricos adequados à resolução de sistemas rígidos de EDOs. A escolha, a implementação e o uso de alguns destes métodos para estimar numericamente o inventário dos radionuclídeos de qualquer cadeia de decaimento radioativo aparece como objetivo específico deste trabalho. Dada uma quantidade $x_{i}\left(t_{j}\right)$ do elemento $i$ da cadeia $(1 \leq i \leq n)$ no instante de tempo $t_{j}$, buscamos uma aproximação numérica para o inventário de todos os radionuclídeos da série em qualquer instante de tempo $t \in \mathbb{R}$. Esta abordagem pode ser utilizada como ferramenta de auxílio na otimização dos processos de produção de radioisótopos e no gerenciamento de rejeitos radioativos e de situações de emergência nuclear, estando as cadeias em equilíbrio ou havendo inserção e retirada de determinadas quantidades dos elementos durante o processo de decaimento.

Os próximos capítulos deste texto apresentam os estudos e resultados obtidos concernentes aos objetivos propostos e estão estruturados da seguinte forma: no Capítulo 2, discutiremos com mais detalhes a classe de EDOs rígidas; no Capítulo 3, apresentaremos a solução analítica para problemas lineares de EDOs, as características necessárias aos métodos numéricos para que sejam utilizados na resolução de equações rígidas e os métodos numéricos que foram implementados neste trabalho (Radau II e Rosenbrock); o Capítulo 4 apresenta os resultados obtidos quando utilizamos os métodos implementados para o cálculo das soluções dos problemas de decaimento radioativo propostos; por fim, são apresentadas algumas considerações acerca do estudo realizado. 


\section{Capítulo 2}

\section{Problemas Rígidos de Equações Diferenciais Ordinárias}

Neste capítulo, tratamos de uma classe de Equações Diferenciais Ordinárias que foram estudadas inicialmente na década de 1950 e atualmente são conhecidas como equações rígidas (do inglês, stiff). Aqui será apresentado o conceito de rigidez.

\subsection{Problemas Rígidos}

Na segunda metade do século XVII, Issac Newton e Gottfried Leibniz publicaram os primeiros estudos notáveis com relação às EDOs. Enquanto o primeiro direcionava sua pesquisa para as aplicações na área da física, o segundo apresentava um viés mais teórico no estudo deste tipo de equações (Sasser, 1992), (Deuflhard e Bornemann, 2002). Durante os séculos seguintes, muitos foram os estudiosos que voltaram sua atenção para técnicas de resolução de EDOs e análises qualitativas de suas soluções. Entre eles, no ano de 1750, Leonhard Euler foi o primeiro a fazer uso de séries de potências para resolver uma EDO, dando origem ao conhecido Método de Euler de primeira ordem. Por outro lado, entre o final do século XIX e o início do século XX, Henri Poincaré formulou uma teoria matemática inovadora que se tornou o ponto de partida para o atual campo da matemática de sistemas dinâmicos.

Esta base teórica sólida, juntamente com o progresso rápido dos computadores e da computação nas últimas décadas, têm possibilitado a resolução de sistemas de EDOs de alta ordem e complexidade. No ano de 1952, Curtiss e Hirschfelder publicaram um trabalho pioneiro sobre a existência de uma importante classe de EDOs que viriam a ser conhecidas como equações rígidas, do inglês, stiff equations, e que apresentavam grandes desafios aos métodos numéricos existentes naquela época (Curtiss e Hirschfelder, 1952). Exemplos de problemas rígidos podem ser encontrados em diversas áreas de aplicação, tais como mecânica celeste de Newton, dinâmica molecular clássica, cinética de reações químicas, circuitos elétricos, física nuclear. É importante deixar claro que a rigidez é uma característica inerente ao fenômeno real e ela independe da técnica utilizada para a resolução das equações que modelam o 
problema.

Uma das maiores dificuldades associadas ao estudo de sistemas diferenciais rígidos é a falta de uma definição matemática precisa do conceito de rigidez. Existem diversas ideias intuitivas sobre o que é rigidez e vários resultados teóricos que dão fundamentação às técnicas propostas para resolução numérica de sistemas rígidos. Estas afirmações e resultados serão apresentados e discutidos nos próximos parágrafos deste capítulo.

Normalmente, um problema rígido exige dos métodos explícitos um tamanho muito pequeno de passo de integração para a garantia de uma solução numérica estável e precisa, impondo o uso de métodos implícitos. Ou seja:

Definição 2.1. Equações diferenciais que descrevem um problema rígido impõem dificuldades às técnicas numéricas explíticas normalmente utilizadas.

Esta foi a primeira constatação feita por Curtiss e Hirschfelder (1952) acerca desta classe de problemas. Naquele trabalho, os autores apresentaram um método satisfatório de solução destas equações, obtido por meio da utilização de um processo de interpolação progressiva. Este esquema consiste em destacar e aproximar uma solução particular da equação diferencial, excluindo as demais soluções gerais. Por meio de uma interpretação geométrica do processo de interpolação progressiva, Curtiss e Hirschfelder (1952) consideram como exemplo a equação diferencial:

$$
\frac{d x(t)}{d t}=5\left(x(t)-t^{2}\right), \quad t \in \mathbb{R}
$$

A solução analítica da equação 2.1 e uma comparação entre o desempenho dos Métodos de Euler Explícito e Implícito para o cálculo de uma solução numérica precisa para esta equação são apresentadas no Apêndice A, onde ratificamos a afirmação de Curtiss e Hirschfelder (1952) que métodos explícitos apresentam maior dificuldade para resolução de equações rígidas.

Com vistas a um conceito matemático mais preciso para rigidez, vamos considerar um Problema de Valor Inicial (PVI) constituído por um sistema de Equações Diferenciais Ordinárias (EDOs) do tipo:

$$
x^{\prime}(t)=f(t, x), \quad x\left(t_{0}\right)=x_{0} \in \mathbb{R}^{d},
$$

onde $(t, x) \in \Omega \subset \mathbb{R}^{d+1}$ e $f: \Omega \rightarrow \mathbb{R}^{d}$. Já que estas equações diferenciais descrevem uma função $x(t)$ indiretamente por meio de sua derivada $x^{\prime}(t)$, é natural que o processo de solução seja interpretado como uma integração. Por isso, comumente se refere ao processo de solução como a integração numérica de problemas de valor inicial. Em muitos casos, a variável $t$ pode ser interpretada fisicamente como tempo, o que caracteriza um PVI de caráter semi-aberto, com $t_{0} \leq t<\infty$, normalmente chamado de problema de evolução. Neste contexto, o vetor $x$ caracteriza o estado do sistema em cada instante de tempo e por isso frequentemente é chamado de estado do problema ou vetor estado.

Buscamos uma solução para a equação $2.2 \mathrm{em}$ um intervalo $I=\{t \in \mathbb{R}: a \leq t \leq b,-\infty<$ $a<b<\infty\}$. O Teorema de Existência e Unicidade de Soluções nos fornece as condições 
necessárias à função $f(t, x)$ para que tenhamos uma única solução de 2.2 no intervalo $I: f$ deve ser contínua e Lipschitziana com relação à segunda variável. Considerando que a função $f$ da equação 2.2 satisfaça tais hipóteses, podemos afirmar que o problema por ela modelado tem uma única solução no intervalo $I$.

Vamos considerar inicialmente o caso em que a função $f(t, x)$ da equação 2.2 caracteriza um sistema linear com coeficientes constantes homogêneo, ou seja:

$$
x^{\prime}(t)=-A x(t), \quad x(0)=x_{0},
$$

onde $A$ é uma matriz constante de dimensão $d \times d$ com autovalores distintos $\lambda_{i} \in \mathbb{C}, i=$ $1, \ldots, d$ e respectivos autovetores $v_{i} \in \mathbb{C}^{d}, i=1, \ldots, d$.

Vamos discretizar o problema contínuo 2.3 considerando um incremento $h>0$ e introduzindo uma malha de pontos equidistantes $t_{n}=n h, n=0,1, \ldots$ Desta forma, a solução $x_{n}=x\left(t_{n}\right)$ da discretização do PVI 2.3 obedece à seguinte relação de recorrência:

$$
x_{n+1}=e^{-A h} x_{n}
$$

Introduzindo a função $S(z)=e^{-z}$, vamos reescrever a equação 2.4 da seguinte forma:

$$
x_{n+1}=S(A h) x_{n}
$$

Agora, considerando uma aproximação $u_{n}$ mais simples possível para $x_{n}, n=1,2, \ldots$, dada pelo Método de Euler, temos:

$$
u_{n+1}=u_{n}-h A u_{n}, \quad n=1,2, \ldots, \quad u_{0}=x_{0} .
$$

Usando a função $K(z)=1-z$, podemos reescrever a equação 2.6 da seguinte forma:

$$
u_{n+1}=u_{n}-h A u_{n}=(1-h A) u_{n}=K(h A) u_{n} .
$$

Na literatura, $K(z)$ é chamado de fator de amplificação ou função de estabilidade do método e $K(A h)$ é o operador de amplificação correspondente ao método descrito por 2.6 (Miranker, 1981).

A diferença entre as equações 2.7 e 2.5 é tomada como o erro global $e_{n}=u_{n}-x_{n}$ do método e obedece à seguinte relação de recorrência:

$$
\begin{aligned}
e_{n+1} & =u_{n+1}-x_{n+1} \\
& =K(h A) u_{n}-S(h A) x_{n} \\
& =K(h A) u_{n}-K(h A) x_{n}+K(h A) x_{n}-S(h A) x_{n} \\
& =K(h A)\left(u_{n}-x_{n}\right)+(K(h A)-S(h A)) x_{n} \\
& =K(h A) e_{n}+T(h A) x_{n},
\end{aligned}
$$


onde $T(z)=K(z)-S(z)$.

Assim, podemos reescrever a equação 2.8 como segue:

$$
e_{n+1}=\sum_{j=0}^{n} K^{j} T x_{n-j},
$$

de onde obtemos o limitante:

$$
\left\|e_{n}\right\| \leq n \max _{0 \leq j \leq n-1}\|K\|^{j} \max _{0 \leq j \leq n-1}\left\|T x_{j}\right\|
$$

Aqui, $\|\cdot\|$ denota alguma norma vetorial ou a norma matricial associada.

Se o método numérico é estável e de ordem $p$, isto é, satisfaz respectivamente as equações:

$$
\begin{gathered}
\|K\| \leq 1, \\
\|T x\|=O\left(h^{p+1}\right)\|x\|,
\end{gathered}
$$

então segue da equação 2.10 que o erro global é de ordem $p$, ou seja, $\left\|e_{n}\right\|=O\left(h^{p}\right)$.

Nos valendo de algumas propriedades de normas matriciais, segue da equação 2.11 que para o Método de Euler, por exemplo, obtemos estabilidade se:

$$
\left|1-\lambda_{i} h\right| \leq 1, \quad i=1, \ldots, d
$$

Assim, quando o $\left|\lambda_{\max }\right|=\max _{1 \leq i \leq d}\left|\lambda_{i}\right|$ for muito grande, a estabilidade do método é satisfeita com uma restrição significativa no tamanho do $h$. Nos valendo destas informações, podemos apresentar uma segunda definição para rigidez:

Definição 2.2. Um sistema rígido é aquele cujo $\left|\lambda_{\text {max }}\right|$ é muito grande, de modo que a estabilidade e o limitante do erro podem ser garantidos simultaneamente somente com um tamanho de h excessivamente pequeno, requerendo muitas iterações do método numérico para resolver o PVI (Miranker, 1981).

Uma alternativa para contornar este problema é a utilização de estratégias de passo adaptativo, onde o tamanho de $h$ varia de acordo com o comportamento da solução do sistema.

Na literatura, a rigidez do sistema 2.3 também é frequentemente definida em função da magnitude dos autovalores associados à matriz dos coeficientes $A$ :

Definição 2.3. Um sistema linear de EDOs é rígido quando a sua taxa de rigidez $\alpha$, definida por:

$$
\alpha=\frac{\max _{1 \leq i \leq d}\left|\operatorname{Re}\left(\lambda_{i}\right)\right|}{\min _{1 \leq i \leq d}\left|\operatorname{Re}\left(\lambda_{i}\right)\right|},
$$


for muito grande (Lambert, 1991).

Porém, esta definição é um tanto restritiva. Primeiramente, observe que uma única equação pode ser rígida, como é o caso da equação 2.1, utilizada como exemplo no trabalho pioneiro de Curtiss e Hirschfelder (1952) sobre equações rígidas. Além disso, se a taxa de decaimento da solução de uma equação for muito grande com relação ao inverso do tempo final de avaliação, esta equação também torna-se rígida. Por outro lado, como mostra Miranker (1981), esta definição também exclui o sistema obviamente rígido correspondente a um oscilador harmônico de alta frequência dado por $x^{\prime \prime}(t)+\omega^{2} x(t)=0$, com $\omega^{2}$ grande. De fato, este sistema pode ser escrito da seguinte forma:

$$
\left[\begin{array}{l}
z^{\prime} \\
x^{\prime}
\end{array}\right]=\left[\begin{array}{cc}
0 & -\omega^{2} \\
1 & 0
\end{array}\right]\left[\begin{array}{l}
z \\
x
\end{array}\right]
$$

de onde segue que os autovalores do sistema são $\pm i \omega$ e a taxa de rigidez do sistema não pode ser calculada. Porém, o sistema é rígido, pois para valores grandes de $\omega$ a solução do sistema tem grandes oscilações em pequenos períodos de tempo e para obtermos uma solução numérica precisa, que acompanhe tais oscilações, é necessário um passo de integração $h$ bastante pequeno.

Outro exemplo retirado do livro de Miranker (1981), mostra a contradição para um sistema linear onde os coeficientes da matriz $A$ dependem da variável $t$ :

$$
\left[\begin{array}{l}
x_{1}^{\prime} \\
x_{2}^{\prime}
\end{array}\right]=\left[\begin{array}{cc}
\sin (\omega t) & \cos (\omega t) \\
\cos (\omega t) & -\sin (\omega t)
\end{array}\right]\left[\begin{array}{l}
x_{1} \\
x_{2}
\end{array}\right] .
$$

A matriz dos coeficientes do sistema 2.16 tem como autovalores \pm 1 e a sua solução varia com frequência $\omega$. Ou seja, a taxa de rigidez do sistema será sempre igual a 1 e o sistema pode ser rígido dependendo do valor de $\omega$, analogamente ao sistema 2.15.

Outro impecílio no uso desta definição aparece na tenativa de sua extensão para sistemas não lineares, mesmo considerando a linearização destes sistemas em torno da condição inicial do problema.

Além das afirmações apresentadas até o momento com respeito ao conceito de rigidez, a primeira comparando o desempenho de métodos explícitos com métodos implícitos e as outras duas relacionadas à magnitude dos autovalores da matriz dos coeficientes do sistema, uma quarta ideia do conceito de rigidez, que vem ao encontro das definições já apresentadas, é:

Definição 2.4. Equações rígidas são aquelas cujas soluções variam em escalas de tempo muito diferentes (Lambert, 1991).

Vários problemas que exemplificam esta ideia podem ser encontrados no capítulo 4 do livro de Hairer e Wanner (1996) e no capítulo 1 do livro de Miranker (1981). Para tais pro- 
blemas rígidos é necessário o controle do passo de integração em função do comportamento das soluções, cuja escala de decaimento pode variar muito.

Neste ponto, é importante deixar claro novamente, que a rigidez é uma característica do próprio problema e das equações diferenciais que o descrevem, não do método utilizado para sua resolução. No decorrer deste texto, iremos considerar como rígido um problema que satisfaça pelo menos uma das definicões de rigidez apresentadas neste capítulo. 


\section{Capítulo 3}

\section{Soluções para os Problemas Rígidos de Equações Diferenciais Ordinárias}

Este capítulo trata sobre as soluções para problemas de EDOs. Mesmo nos casos em que a solução analítica existe, é importante lembrar que existem dificuldades em considerá-la para um sistema com um número muito grande de equações. Além disso, existem vantagens no uso de métodos numéricos para a resolução destes sistemas no que diz respeito à facilidade de alterações na modelagem, nas condições iniciais e na quantidade de equações. Caso estes problemas apresentem rigidez, torna-se necessário o uso de métodos numéricos específicos para este tipo de problema.

Aqui, apresentamos a solução analítica para sistemas lineares de Equações Diferenciais Ordinárias de Primeira Ordem com coeficientes constantes e as características adequadas aos métodos numéricos utilizados para o cálculo das soluções aproximadas de sistemas rígidos de EDOs. Estudamos conceitos importantes relacionados a tais técnicas numéricas, como A-estabilidade e ordem de convergência dos métodos. Apresentamos também as técnicas numéricas implementadas neste trabalho e as justificativas pela sua escolha.

\subsection{Solução Analítica}

A solução para um sistema linear de Equações Diferenciais Ordinárias de Primeira Ordem com coeficientes constantes de dimensão $d$ é dada em função dos autovalores $\lambda_{i} \in \mathbb{C}, i=$ $1, \ldots, d$ associados à matriz dos coeficientes $A_{d \times d}$ e seus respectivos autovetores $v_{i} \in \mathbb{C}^{d}, i=$ $1, \ldots, d$ (Tello, 1979). Ou seja, a solução da EDO $x^{\prime}(t)=A x(t)$ é dada por:

$$
x(t)=k_{0}+k_{1} \exp \left(\lambda_{1} t\right) v_{1}+\cdots+k_{d} \exp \left(\lambda_{d} t\right) v_{d}
$$

onde as constantes $k_{i}, i=1, \ldots, d$, são determinadas em função das condições inicias do sistema.

Na área da Física Nuclear, foi Bateman quem adaptou esta solução analítica para o caso de um sistema linear no qual cada elemento da série decai para outro único elemento 
(Bateman, 1910). Por este motivo, as equações que descrevem este tipo de problema de decaimento são conhecidas pelos físicos nucleares como Equações de Bateman. Para cadeias onde existe a probabilidade de decaimentos múltiplos ainda é possível utilizar esta solução realizando o desdobramento e acompanhando cada decaimento (Cetnar, 2006). Considerando uma cadeia linear com $n$ elementos $x_{1}(t), x_{2}(t), \ldots, x_{n}(t)$, cujas constantes de decaimento são, respectivamente, $\lambda_{1}(t), \lambda_{2}(t), \ldots, \lambda_{n}(t)$, e assumindo-se que no instante inicial $t=0$ existe apenas uma quantidade $x_{1}(0)=x_{1}^{0}$ do primeiro elemento, a solução proposta por Bateman para cada um dos elementos é da forma:

$$
\begin{gathered}
x_{1}(t)=x_{1}^{0} e^{-\lambda_{1} t}, \\
x_{2}(t)=x_{1}^{0} \lambda_{1}\left[\frac{e^{-\lambda_{1} t}}{\left(\lambda_{2}-\lambda_{1}\right)}+\frac{e^{-\lambda_{2} t}}{\left(\lambda_{1}-\lambda_{2}\right)}\right], \\
\vdots \\
x_{n}(t)=x_{1}^{0} \prod_{k=1}^{n-1} \lambda_{k} \sum_{j=1}^{n}\left[\frac{e^{-\lambda_{j} t}}{\prod_{p=1, p \neq j}^{n}\left(\lambda_{p}-\lambda_{j}\right)}\right] .
\end{gathered}
$$

Para cadeias mais complexas, onde a quantidade de elementos e de ramificações é muito grande e as constantes de decaimento apresentam ordens de grandeza com magnitudes muito diferentes, de modo que a diferença entre as taxas na equação 3.4 tenda para infinito, uma solução analítica do sistema de equações diferencias torna-se inviável e a utilização de métodos numéricos específicos para problemas rígidos é necessária.

\subsection{Soluções Numéricas}

Ao solucionarmos numericamente um Problema de Valor Inicial de EDOs do tipo 2.2 no intervalo $I=\{t \in \mathbb{R}: a \leq t \leq b,-\infty<a<b<\infty\}$, objetivamos determinar uma aproximação da sua solução exata em um conjunto discreto finito de pontos definido por:

$$
t_{0}=a, t_{1}=t_{0}+\Delta t_{1}, t_{2}=t_{1}+\Delta t_{2}, \ldots, t_{n}=t_{n-1}+\Delta t_{n}=b
$$

onde cada $\Delta t_{k}, 1 \leq k \leq n$, denota o passo de integração necessário para irmos de $t_{k-1}$ até $t_{k}$.

De agora em diante, vamos buscar uma solução numérica para o PVI 2.2 admitindo que o mesmo satisfaz as condições do Teorema de Existência e Unicidade de Soluções, ou seja, o mesmo possui uma única solução.

Com base nas considerações do Capítulo 2, é natural compreendermos porque a reação dos analistas numéricos tenha sido focar inicialmente em derivações de métodos implícitos 
para desenvolver métodos eficientes para a resolução numérica de sistemas rígidos. Uma família bastante conhecida de métodos numéricos para trabalhar com equações diferenciais é a família dos Métodos de Passo Múltiplo Lineares (MPMLs). Segundo Miranker (1981), as primeiras abordagens de resolução de problemas rígidos foram feitas com métodos desta classe e para muitos problemas esta é ainda uma boa estratégia. É importante destacar inclusive, que o método proposto por Curtiss e Hirschfelder (1952) em seu trabalho pioneiro era um Método de Passo Múltiplo Linear (MPML) implícito. Além disso, a maioria dos avanços dos métodos destinados à resolução de problemas rígidos são estimulados pelos êxitos e fracassos evidentes destes métodos, como veremos nos próximos parágrafos.

Primeiramente, vamos definir um Método de Passo Múltiplo Linear:

Definição 3.1. Um Método de Passo Múltiplo Linear (MPML) de k passos é da forma:

$$
\mathbb{F}\left(x_{n}\right)=\sum_{j=0}^{k} \alpha_{j} x_{n+j}-h \sum_{j=0}^{k} \beta_{j} f_{n+j}=0,
$$

onde $f_{n}=f\left(t_{n}, x_{n}\right)$, sendo $f$ a função do PVI 2.2. Na equação 3.6, se $\beta_{k}=0$, o método é explicito, e se $\beta_{k} \neq 0$, o método é implícito.

Os métodos de passo múltiplo mais conhecidos são os BDF (Backward Differentiation Formulae - Fórmula de Diferenciação Regressiva) e os Métodos de Adams. Estes métodos podem ser deduzidos, respectivamente, por interpolação numérica da função que descreve a derivada do problema ou por uma aproximação da forma integral do problema através de fórmulas de quadratura numérica. A seguir, são apresentados exemplos destes métodos para o caso em que $k=3$ (Hairer et al., 1987).

\section{Método BDF Explícito de 3 passos:}

$$
\frac{1}{3} x_{n+3}+\frac{1}{2} x_{n+2}-x_{n+1}+\frac{1}{6} x_{n}-h f_{n+2}=0
$$

\section{Método BDF Implícito de 3 passos:}

$$
\frac{11}{6} x_{n+3}-3 x_{n+2}+\frac{3}{2} x_{n+1}-\frac{1}{3} x_{n}-h f_{n+3}=0
$$

Método de Adams Explícito de 3 passos:

$$
x_{n+3}-x_{n+2}-h\left(\frac{23}{12} f_{n+2}-\frac{16}{12} f_{n+1}+\frac{5}{12} f_{n}\right)=0
$$

\section{Método de Adams Implícito de 3 passos:}

$$
x_{n+3}-x_{n+2}-h\left(\frac{9}{24} f_{n+3}+\frac{19}{24} f_{n+2}-\frac{5}{24} f_{n+1}+\frac{1}{24} f_{n}\right)=0
$$

Nos MPMLs, cada aproximação $x_{n+k}$ é obtida de 3.6 resolvendo-se uma equação da 
forma:

$$
\alpha_{k} x_{n+k}-h \beta_{k} f_{n+k}=\text { constante } \in \mathbb{R} .
$$

No caso explícito, resolver a equação 3.11 requer somente uma divisão por $\alpha_{k}$. Porém, no caso implícito, 3.11 representa um sistema de equações finitas que deve ser resolvido por um procedimento numérico, como por exemplo, o método iterativo de Newton. Além disso, os primeiros pontos, $x_{0}, x_{1}, \ldots, x_{k-1}$, que são necessários para calcular a aproximação $x_{k}$ também são considerados como condições iniciais e devem ser determinados por alguma estratégia independente, que deve ser precisa e estável.

Vejamos alguns conceitos relacionados à consistência, estabilidade e convergência dos Métodos de Passo Múltiplo Lineares:

Definição 3.2. Um Método de Passo Múltiplo Linear é dito de ordem p se:

$$
\left\|\mathbb{F}\left(x\left(t_{n}\right)\right)\right\|=O\left(h^{p}\right),
$$

onde $x(t)$ é qualquer solução de $x^{\prime}=f(t, x)$. Além disso, o método é dito consistente se 3.12 é válida com $p \geq 1$.

A consistência e a estabilidade dos Métodos de Passo Múltiplo Lineares estão relacionadas, de maneira geral, com a solução de equações de diferenças lineares, com o controle das raízes de um polinômio naturalmente associado aos MPMLs e com os polinômios característicos destes métodos. Introduziremos agora, os polinômios $\rho$ e $\sigma$, respectivamente conhecidos como primeiro polinômio característico e segundo polinômio característico associados ao método 3.6:

$$
\rho(\omega)=\sum_{j=0}^{k} \alpha_{j} \omega^{j}, \quad \sigma(\omega)=\sum_{j=0}^{k} \beta_{j} \omega^{j} .
$$

Vamos supor que estes polinômios são primos entre si, ou seja, $(\rho \mid \sigma)=1$. Desta forma, podemos enunciar o seguinte teorema, que relaciona tais polinômios com a noção de consistência:

Teorema 3.1. Um MPML é consistente se, e somente se, $\rho(1)=0$ e $\rho^{\prime}(1)=\sigma(1)$.

A demonstração do Teorema 3.1 pode ser encontrada em (Lambert, 1991) e é feita a partir da expansão em Série de Taylor da solução $x(t)$ do Problema de Cauchy aplicada à equação do método 3.6.

Considerando o Método BDF Implícito de 3 passos (3.8) como exemplo para aplicação do Teorema 3.1, é possível verificar a consistência do método. De fato, o primeiro polinômio característico do método é dado por:

$$
\rho(\omega)=-\frac{1}{3}+\frac{3}{2} \omega-3 \omega^{2}+\frac{11}{6} \omega^{3} .
$$


Derivando $\rho(\omega)$ com relação à variável $\omega$, temos:

$$
\rho^{\prime}(\omega)=\frac{3}{2}-6 \omega+\frac{11}{2} \omega^{2}
$$

Além disso, o segundo polinômio característico do método é dado por:

$$
\sigma(\omega)=\omega^{3}
$$

Portanto, segue da equação 3.14 que $\rho(1)=0$, da equação 3.15 que $\rho^{\prime}(1)=1$ e da equação 3.16 que $\sigma(1)=1$. Desta forma, concluímos pelo Teorema 3.1 que o Método BDF Implícito de 3 passos é consistente.

Analogamente, verificamos que o Método de Adams Implícito de 3 passos (3.10) também é consistente. Observe que o primeiro e o segundo polinômios característicos do método são dados por:

$$
\begin{gathered}
\rho_{A}(\omega)=-\omega^{2}+\omega^{3} \Rightarrow \rho_{A}^{\prime}(\omega)=-2 \omega+3 \omega^{2}, \\
\sigma_{A}(\omega)=\frac{1}{24}-\frac{5}{24} \omega+\frac{19}{24} \omega^{2}+\frac{9}{24} \omega^{3} .
\end{gathered}
$$

Segue das equações 3.17 e 3.18 que $\rho_{A}(1)=0, \rho_{A}^{\prime}(1)=1$ e $\sigma_{A}(1)=1$. Portanto, pelo Teorema 3.1, o Método de Adams Implícito de 3 passos é consistente.

A estabilidade dos MPMLs também está relacionada ao polinômio $\rho(\omega)$. O Teorema 3.2 mostra quais são as condições necessárias e suficientes às raízes de $\rho$ para que a estabilidade do método seja garantida.

Teorema 3.2. Um MPML é estável se, e somente se, nenhuma raíz de $\rho(\omega)$ tiver módulo maior do que 1 e toda a raiz com módulo igual a 1 for uma raiz simples.

Aplicando o Teorema 3.2 na equação 3.8, que define o Método BDF Implícito de 3 passos, é possível verificar que tal método é estável. De fato, as raízes do primeiro polinômio característico do método são: $\omega_{1}=1$ e $\omega_{2,3}=\frac{7}{22} \pm i \frac{\sqrt{39}}{22}$. Então, $\left|\omega_{1}\right|=1$ e $\left|\omega_{2,3}\right|=\sqrt{\frac{2}{11}} \approx$ 0,4264, de onde segue que o Método BDF Implícito de 3 passos é estável.

Para o Método de Adams Implícito de 3 passos temos como raízes do primeiro polinômio característico $\omega_{1,2}=0$ e $\omega_{3}=1$, de onde concluímos, pelo Teorema 3.2, que o método é estável, uma vez que $\left|\omega_{1,2}\right|=0<1$ e $\left|\omega_{3}\right|=1$.

Agora que já sabemos identificar quando um método de passo múltiplo é consistente e estável, vamos relacionar estas propriedades com a convergência deste método. A convergência de um Método de Passo Múltiplo Linear é definida da seguinte maneira:

Definição 3.3. Um MPML é convergente se, para toda $f$ Lipschitziana do Problema de Cauchy, tivermos:

$$
\lim _{h \longrightarrow 0} \max \left\|e_{n}\right\|=0,
$$

onde $h$ é o passo de integração e $e_{n}=x_{n}-x\left(t_{n}\right)$ é o erro global do método. 
Isso posto, podemos apresentar o teorema a seguir, que relaciona os conceitos de consistência, estabilidade e convergência de MPMLs:

Teorema 3.3. Um MPML é convergente se, e somente se, for consistente e estável.

Considerando novamente como exemplo os Métodos BDF Implícito de 3 passos e Adams Implícito de 3 passos, concluímos através do Teorema 3.3 que os mesmos são convergentes, uma vez que as análises realizadas sobre seus polinômios característicos e suas respectivas raízes mostraram que os métodos são consistentes (Teorema 3.1) e estáveis (Teorema 3.2).

Agora, vamos estudar a região de estabilidade dos métodos numéricos utilizados para resolução de Equações Diferenciais Ordinárias. Para tal, iremos considerar a seguinte definição:

Definição 3.4. Um MPML é A-estável (Absolutamente estável) se todas as soluções da equação de diferenças gerada por este método aplicado na equação teste

$$
x^{\prime}=\lambda x, \quad \lambda \in \mathbb{C},
$$

tendem a zero quando $n \longrightarrow \infty$ para todo $\lambda$ com parte real negativa e para todo $h$ fixo.

Para determinarmos quais MPMLs são A-estáveis vamos inserir a equação teste 3.20 na equação 3.6, que define o método. A equação de diferenças linear resultante é:

$$
\sum_{j=o}^{k}\left(\alpha_{j}-q \beta_{j}\right) x_{n+j}=0, \quad q=\lambda h .
$$

A equação característica correspondente à equação 3.21 é:

$$
\rho(\omega)-q \sigma(\omega)=0
$$

de onde segue que

$$
q(\omega)=\frac{\rho(\omega)}{\sigma(\omega)}
$$

Desta forma, podemos enunciar o seguinte resultado, que relaciona os polinômios $\rho$ e $\sigma$ com a A-estabilidade do método:

Teorema 3.4. O MPML dado pela equação 3.6 é A-estável se, e somente se, todas as raízes de $\sigma$ tiverem módulo menor ou igual a 1 e a parte real de 3.23 for maior ou igual a zero para todo w com módulo maior do que 1.

Deste modo, pode parecer que um problema rígido é facilmente resolvido ao considerarmos Métodos de Passo Múltiplo Lineares A-estáveis de altas ordens. Porém, se aplicarmos o Teorema 3.4 ao método BDF Implícito de 3 passos, que temos considerado como exemplo até aqui, é possível verificar que tal método não possui a propriedade de A-estabilidade. 
De fato, basta considerarmos $\omega=0,3+0,96 i$ na equação 3.23 para vermos que $q(w)=$ $-0,016919+1,80126 i$, de onde segue que $|\omega| \approx 1,00578>1$ e $\operatorname{Re}(q(\omega))=-0,016919<0$. Assim, pelo Teorema 3.4, o Método BDF Implícito de 3 passos não é A-estável.

É possível verificar também que o Método de Adams Implícito de 3 passos não é Aestável, visto que uma das raízes do seu segundo polinômio característico é $\omega_{1} \approx-2,3658$, cujo módulo é maior do que 1, o que contradiz o Teorema 3.4. Na verdade, não existem MPMLs A-estáveis com ordem maior do que 2, como mostra o Teorema 3.5.

Teorema 3.5. São verdadeiras as seguintes afirmações (Dahlquist, 1963):

(i) Um Método de Passo Múltiplo Linear Explícito não pode ser A-estável;

(ii) A ordem de um Método de Passo Múltiplo Linear A-estável não excede 2;

(iii) Se a ordem de um Método de Passo Múltiplo Linear A-estável for igual a 2, então a constante de erro do método é menor ou igual a $-\frac{1}{12}$.

Segundo Cash (2003), este teorema é indiscutivelmente um dos mais importantes já publicados no campo da computação para problemas rígidos, pois mostra a dificuldade de desenvolver MPMLs eficientes para este tipo de problema e provavelmente ajudou muitos pesquisadores a focar seus estudos em outros métodos A-estáveis de alta ordem para resolução de sistemas rígidos.

Assim, temos duas alternativas: enfraquecer a A-estabilidade ou partir para outra classe de métodos que sejam A-estáveis para altas ordens. Vamos considerar primeiramente o enfraquecimento da A-estabilidade.

Na maior parte dos casos, os MPML falham quanto à A-estabilidade para valores de $\lambda$ na equação teste (3.20) muito próximos de ser puramente imaginários. Assim surge a noção de $\mathrm{A}(\alpha)$-estabilidade. Vamos desconsiderar tais valores de $\lambda$ e considerar a A-estabilidade com relação a um subconjunto do semiplano esquerdo do plano complexo que exclue o eixo imaginário. Vamos substituir o semiplano esquerdo por um cone $S_{\alpha}$ com vértice na origem centrado no eixo real negativo e com meio ângulo $\alpha$, conforme a Figura 3.1.

Definição 3.5. Um MPML é $A(\alpha)$-estável, $0<\alpha<\frac{\pi}{2}$, se todas as soluções da equação de diferenças obtida a partir da equação do método aplicada na equação teste 3.20 tendem a zero quando $n \longrightarrow \infty$ para cada $h>0$ fixo e para todo $\lambda \neq 0$, onde

$$
q \equiv \lambda h \in S_{\alpha} \equiv\{q:|\arg (-q)|<\alpha, q \neq 0\}
$$

Uma das razões pela qual a definição 3.5 é bastante útil é o fato de que muitos problemas de Equações Diferenciais Ordinárias possuem Jacobiana com autovalores pertencentes a uma região como $S_{\alpha}$, permitindo o uso de métodos que $\mathrm{A}(\alpha)$-estáveis que convergem para a 


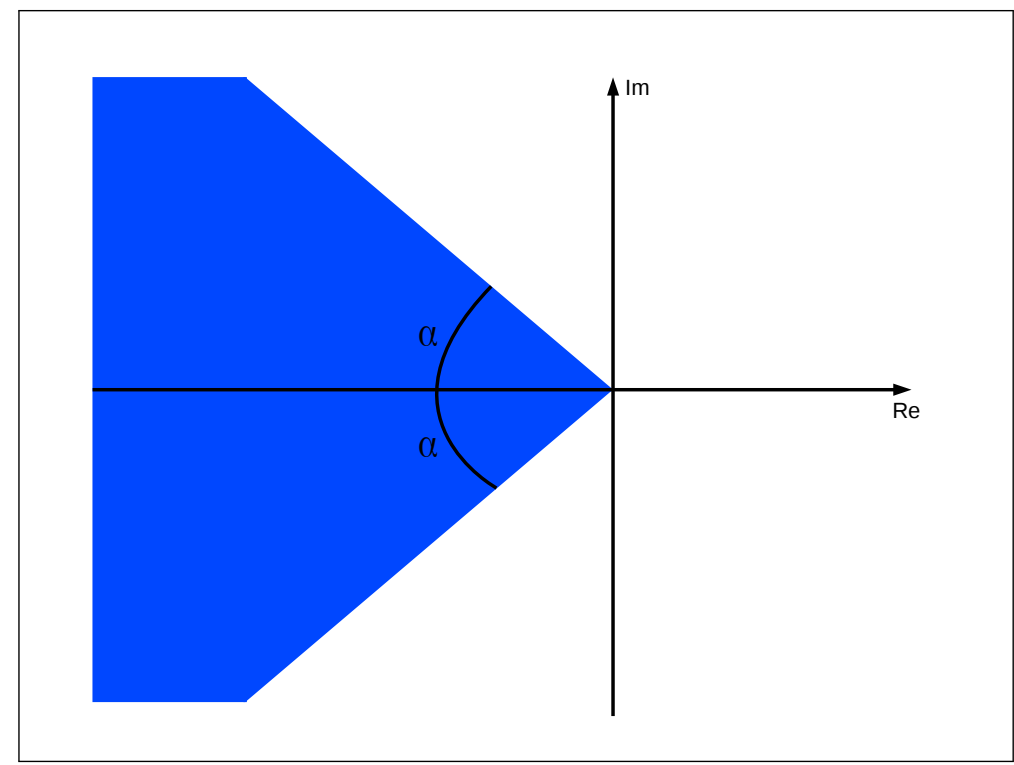

Figura 3.1: Região $S_{\alpha}$ (em azul) de $A(\alpha)$-estabilidade.

solução do problema. Os Métodos de Passo Múltiplo Lineares $\mathrm{A}(\alpha)$-estáveis mais conhecidos são os métodos BDF. Porém, os métodos BDF A $(\alpha)$-estáveis não ultrapassam a ordem 6 e quanto maior for a sua ordem, menor é o ângulo $\alpha$ referente à $\mathrm{A}(\alpha)$-estabilidade, de modo que métodos $\mathrm{BDF}$ com ordem $p \geq 7$ não são $\mathrm{A}(\alpha)$-estáveis para nenhum valor de $\alpha$. $\mathrm{A}$ Tabela 3.1 mostra a relação da ordem $p$ dos métodos BDF e o ângulo $\alpha$ da sua região de $\mathrm{A}(\alpha)$-estabilidade. A Figura 3.2 mostra as regiões de estabilidade dos métodos BDF Implícitos.

\begin{tabular}{ccccccc}
\hline Ordem $p$ & 1 & 2 & 3 & 4 & 5 & 6 \\
\hline Ângulo $\alpha$ & $90^{0}$ & $90^{0}$ & $86.03^{0}$ & $73.35^{0}$ & $51.84^{0}$ & $17.84^{0}$ \\
\hline
\end{tabular}

Tabela 3.1: Relação entre a ordem $p$ de um método BDF e sua $A(\alpha)$-estabilidade.

A Figura 3.3 mostra as regiões de estabilidade dos métodos de Adams implícitos. Note que os métodos de Adams de ordens superiores não possuem nem mesmo a propriedade de $\mathrm{A}(\alpha)$-estabilidade.

Dada a impossibilidade de obtermos MPMLs de altas ordens e absolutamente estáveis, a nossa segunda alternativa é considerar métodos de outra classe que sejam de altas ordens e A-estáveis, como por exemplo, alguns métodos de passo único do tipo Runge-Kutta (RK). O uso disseminado dos métodos do tipo RK em diferentes áreas aplicadas e a sua estabilidade nos levam a considerá-los como ponto de partida para a construção de métodos de passo único eficientes para resolução de problemas rígidos de EDOs. Vários estudos mostram a eficiência de métodos de passo único para resolução de problemas rígidos (Kaps e Rentrop, 1979), (Sandu et al., 1997), (Hairer e Wanner, 1999), (Loch et al., 2013c), (Brugnano et al., 2015), (Liao, 2015).

Na Física Nuclear, os métodos de Runge-Kutta explícitos, tais como RK 4-4 e RK 


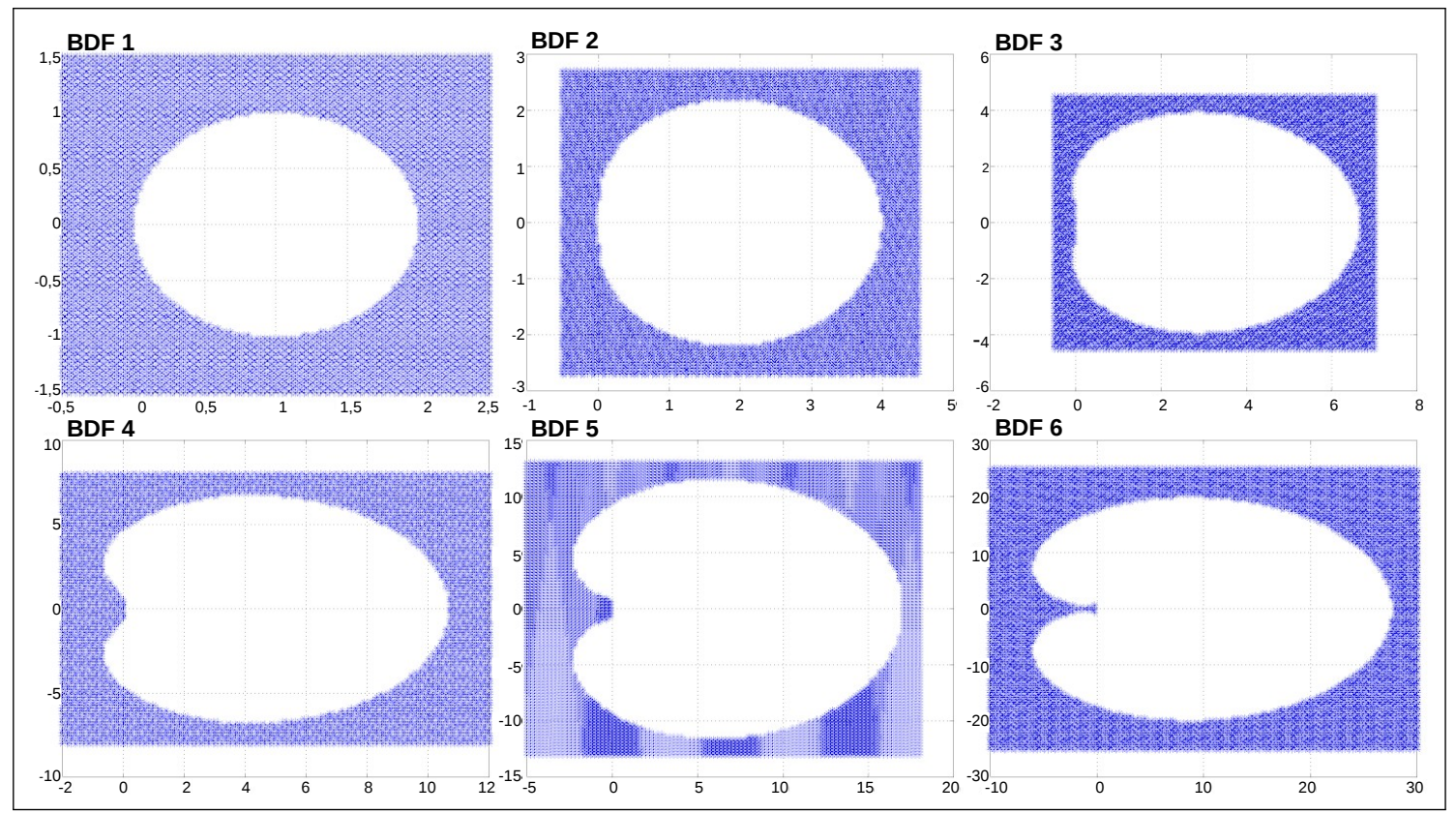

Figura 3.2: Região de estabilidade dos Métodos BDF Implícitos (em azul).

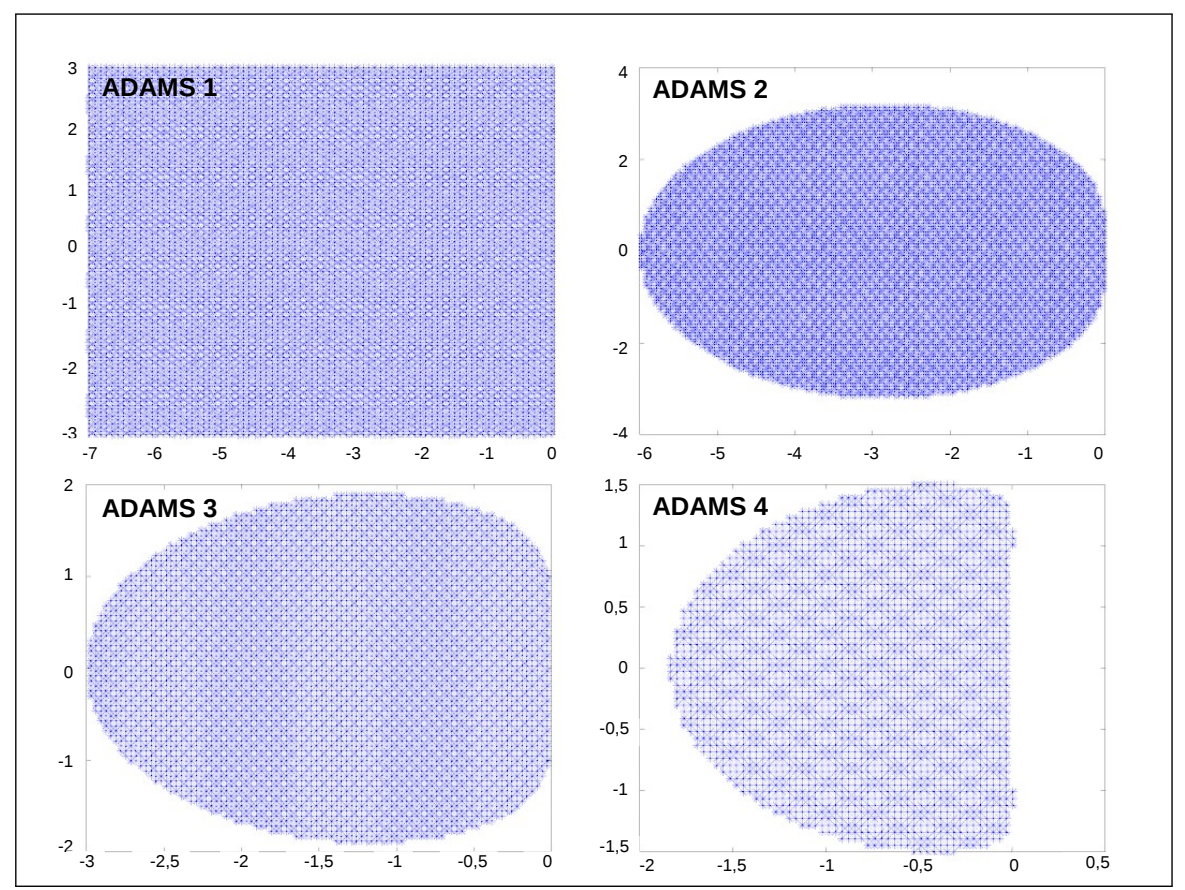

Figura 3.3: Região de estabilidade dos Métodos de Adams Implícitos (em azul).

4-5, são bastante utilizados para resolução de EDOs (de Carvalho, 2006), (Claro, 2011), (Isotani et al., 2012), (Takai e Hagino, 2015). Porém, vimos no capítulo 2 que problemas rígidos sugerem o uso de métodos implícitos para sua resolução. Desta forma, vamos dedicar as próximas páginas deste texto para o estudo de métodos de passo único absolutamente estáveis do tipo Runge-Kutta e suas respectivas implementações. 
Definição 3.6. Um método Runge-Kutta de s-estágios $(s \in \mathbb{N})$ é dado por:

$$
\kappa_{i}=h f\left(t_{0}+\delta_{i} h, x_{0}+\sum_{j=1}^{s} \alpha_{i j} \kappa_{j}\right), \quad i=1, \ldots, s, \quad x_{1}=x_{0}+\sum_{i=1}^{s} \beta_{i} \kappa_{i},
$$

onde $f(t, x)$ é a função do Problema de Valor Inicial, $\left(t_{0}, x_{0}\right)$ é a condição inicial do problema $e h>0$ é o passo de integração do método. Quando $\alpha_{i j}=0$ para $i \leq j$ temos um método $R K$ explícito. Se $\alpha_{i j}=0$ para $i<j$ e pelo menos um $\alpha_{i i} \neq 0$, nós temos um método Runge-Kutta diagonalmente implícito (ou semi-implícito). Caso contrário, temos um método Runge-Kutta implicito.

Usualmente, as constantes $\delta_{i}, i=1, \ldots, s$, satisfazem as seguintes equações:

$$
\delta_{i}=\sum_{j=1}^{s} \alpha_{i j}
$$

Além disso, costuma-se representar o método RK dado pela equação 3.25 em uma matriz proposta por Butcher (1964a) da seguinte forma:

$$
\begin{array}{r|cccc}
\delta_{1} & \alpha_{11} & \alpha_{12} & \ldots & \alpha_{1 s} \\
\delta_{2} & \alpha_{21} & \alpha_{22} & \ldots & \alpha_{2 s} \\
\vdots & \vdots & \vdots & \ddots & \vdots \\
\delta_{s} & \alpha_{s 1} & \alpha_{s 2} & \ldots & \alpha_{s s} \\
\hline & \beta_{1} & \beta_{2} & \ldots & \beta_{s}
\end{array}
$$

Tabela 3.2: Matriz de Butcher para o método RK 3.25.

Para se obter um método Runge-Kutta de ordem $p$, expandimos a equação 3.25 em série de Taylor até o termo de ordem $p$ desejada e igualamos a expansão com a série de Taylor da solução exata correspondente ao PVI. Os cálculos detalhados do desenvolvimento de um método Runge-Kutta podem ser encontrados em Hairer et al. (1987), Lambert (1991), Stoer e Bulirsh (1996) e Roma e Nós (2012).

Definição 3.7. Um método Runge-Kutta do tipo 3.25 tem ordem p se

$$
\left\|x\left(t_{0}+h\right)-x_{1}\right\| \leq K h^{p+1}
$$

isto é, se a série de Taylor para a solução exata $x\left(t_{0}+h\right)$ e a aproximação $x_{1}$ coincidem até o termo $h^{p}$.

Assim como nos MPMLs, a convergência de um método de Runge-Kutta se dá em função do seu erro global de discretização, de modo que o método será convergente se, e somente se, seu erro global dado pela diferença entre a solução exata e a solução aproximada calculada 
pelo método tender a zero quando o tamanho do passo de integração tender também para zero.

A estabilidade dos métodos RK também é estudada como nos MPMLs, aplicando-se a equação de diferenças do método na equação teste 3.20. Uma das grandes vantagens dos métodos de passo único RK com relação aos MPMLs é que eles podem ser de altas ordens e A-estáveis, de modo que a solução aproximada por eles calculada convirja para a solução exata do problema, coincidindo com ela até os termos da ordem do método.

As próximas sessões deste capítulo são destinadas ao estudo específico dos métodos RK A-estáveis implementados neste trabalho. A sessão 3.2.1 versa sobre o método RK implícito baseado nas fórmulas de quadratura de Radau (1880) e a sessão 3.2 .2 apresenta o método RK semi-implícito proposto por Rosenbrock (1963).

\subsubsection{Métodos de Radau}

Em 1964, Butcher propôs o desenvolvimento de métodos do tipo Runge-Kutta baseados nas fórmulas de quadratura de Radau (Butcher, 1964b). Dentre eles, o método Radau II considera que $\delta_{1}, \ldots, \delta_{s}$ da equação 3.25 são as raízes de:

$$
\frac{d^{s-1}}{d t^{s-1}}\left(t^{s-1}(t-1)^{s}\right)
$$

Além disto, os $\beta_{i}$ e $\alpha_{i j}, i, j=1, \ldots, s$, do método 3.25 são escolhidos de modo que satisfaçam as seguintes condições (Hairer e Wanner, 1996):

$$
\begin{gathered}
B(p): \sum_{i=1}^{s} \beta_{i} \delta_{i}^{q-1}=\frac{1}{q}, \quad q=1, \ldots, p \\
C(\eta): \sum_{j=1}^{s} \alpha_{i j} \delta_{i}^{q-1}=\frac{\delta_{i}^{q}}{q}, \quad i=1, \ldots, s, \quad q=1, \ldots, \eta ; \\
D(\zeta): \quad \sum_{i=1}^{s} \beta_{i} \delta_{i}^{q-1} \alpha_{i j}=\frac{\beta_{j}}{q}\left(1-\delta_{j}^{q}\right), \quad j=1, \ldots, s, \quad q=1, \ldots, \zeta,
\end{gathered}
$$

onde $B(p), C(\eta)$ e $D(\zeta)$ são as fórmulas de quadratura de Radau de ordem $p, \eta$ e $\zeta$ respectivemente. A ordem de convergência do método de Radau II é determinada pela equação 3.29.

Vamos calcular os coeficientes do método de Radau II de 3 estágios. Considerando $s=3$ na equação 3.28 , temos que os valores de $\delta_{i}, i=1,2,3$, são as raízes do polinômio:

$$
\frac{d^{2}}{d t^{2}}\left(t^{2}(t-1)^{3}\right)=20 t^{3}-36 t^{2}+18 t-2
$$

de onde segue que:

$$
\delta_{1}=\frac{4-\sqrt{6}}{10}, \quad \delta_{2}=\frac{4+\sqrt{6}}{10}, \quad \delta_{3}=1
$$


Para determinarmos os valores de $\beta_{i}, i=1,2,3$, do Método de Radau II de 3 estágios substituímos os valores encontrados para $\delta_{i}, i=1,2,3$, nas equações definidas por 3.29 até $q=3$, uma vez que precisamos três equações linearmente independentes para determinarmos o valor de cada $\beta$. Desta forma, $\beta_{1}, \beta_{2}$ e $\beta_{3}$ são as soluções do seguinte sistema linear:

$$
\left[\begin{array}{ccc}
1 & 1 & 1 \\
\frac{4-\sqrt{6}}{10} & \frac{4+\sqrt{6}}{10} & 1 \\
\left(\frac{4-\sqrt{6}}{10}\right)^{2} & \left(\frac{4+\sqrt{6}}{10}\right)^{2} & 1
\end{array}\right]\left[\begin{array}{c}
\beta_{1} \\
\beta_{2} \\
\beta_{3}
\end{array}\right]=\left[\begin{array}{c}
1 \\
\frac{1}{2} \\
\frac{1}{3}
\end{array}\right] .
$$

Portanto, temos:

$$
\beta_{1}=\frac{16-\sqrt{6}}{36}, \quad \beta_{1}=\frac{16+\sqrt{6}}{36}, \quad \beta_{3}=\frac{1}{9} .
$$

Agora, resta calcularmos os valores de $\alpha_{i j}$, para $i=1,2,3$ e $j=1,2,3$. Estes valores são determinados substituindo $\delta_{1}, \delta_{2}, \delta_{3}, \beta_{1}, \beta_{2}$ e $\beta_{3}$ nas equações 3.30 e 3.31 para garantir a convergência do método. Destarte, a matriz de Butcher resultante para o método Radau II de 3 estágios fica conforme a Tabela 3.3.

\begin{tabular}{r|ccc}
$\frac{4-\sqrt{6}}{10}$ & $\frac{88-7 \sqrt{6}}{360}$ & $\frac{296-169 \sqrt{6}}{1800}$ & $\frac{-2+3 \sqrt{6}}{225}$ \\
$\frac{4+\sqrt{6}}{10}$ & $\frac{296+169 \sqrt{6}}{1800}$ & $\frac{88+7 \sqrt{6}}{360}$ & $\frac{-2-3 \sqrt{6}}{225}$ \\
1 & $\frac{16-\sqrt{6}}{36}$ & $\frac{16+\sqrt{6}}{36}$ & $\frac{1}{9}$ \\
\hline & $\frac{16-\sqrt{6}}{36}$ & $\frac{16+\sqrt{6}}{36}$ & $\frac{1}{9}$
\end{tabular}

Tabela 3.3: Matriz de Butcher para o Método Radau II de 3 estágios.

Observe que a ordem de convergência do método de Radau II de 3 estágios é 5, uma vez que para os valores de $\beta_{1}, \beta_{2}$ e $\beta_{3}$ encontrados na resolução do sistema 3.34, a equação 3.29 é satisfeita também para $p=4$ e $p=5$. Na verdade, é possível relacionar o número de estágios de um método Radau II com a sua ordem de convergência. O teorema a seguir generaliza a relação entre o número de estágios $s$ e a ordem de convergência $p$ :

Teorema 3.6. O método Radau II de s estágios tem ordem $p=(2 s-1)$. Além disso, o método é A-estável.

A demonstração do Teorema 3.6 é feita com base nas propriedades das quadraturas de Radau e pode ser encontrada em Butcher (1964b) e Hairer e Wanner (1996). Segundo este teorema, além do método Radau II de 3 estágios ter ordem 5 ele também é A-estável. De fato, a região de estabilidade deste método está representada em azul na Figura 3.4, onde é possível verificar que a mesma compreende todo o semiplano esquerdo. Como vimos anteriormente, a região de estabilidade de um método RK também é encontrada através da equação que define o método aplicada na equação teste 3.20. Com esta substituição é 
possível escrevermos o método da seguinte forma:

$$
x_{n+1}=K(h \lambda) x_{n}=K(z) x_{n},
$$

onde $K(z)$ é conhecida como a função de estabilidade do método 3.25, conforme visto no Capítulo 2. Deste modo, a região de estabilidade do método fica determinada por:

$$
S=\{z \in \mathbb{C}:|K(z)| \leq 1\}
$$

Para o método Radau II de 3 estágios e ordem 5 temos a seguinte função de estabilidade:

$$
K(z)=\frac{1+\frac{2 z}{5}+\frac{z^{2}}{20}}{1-\frac{3 z}{5}+\frac{3 z^{2}}{20}-\frac{z^{3}}{60}} .
$$

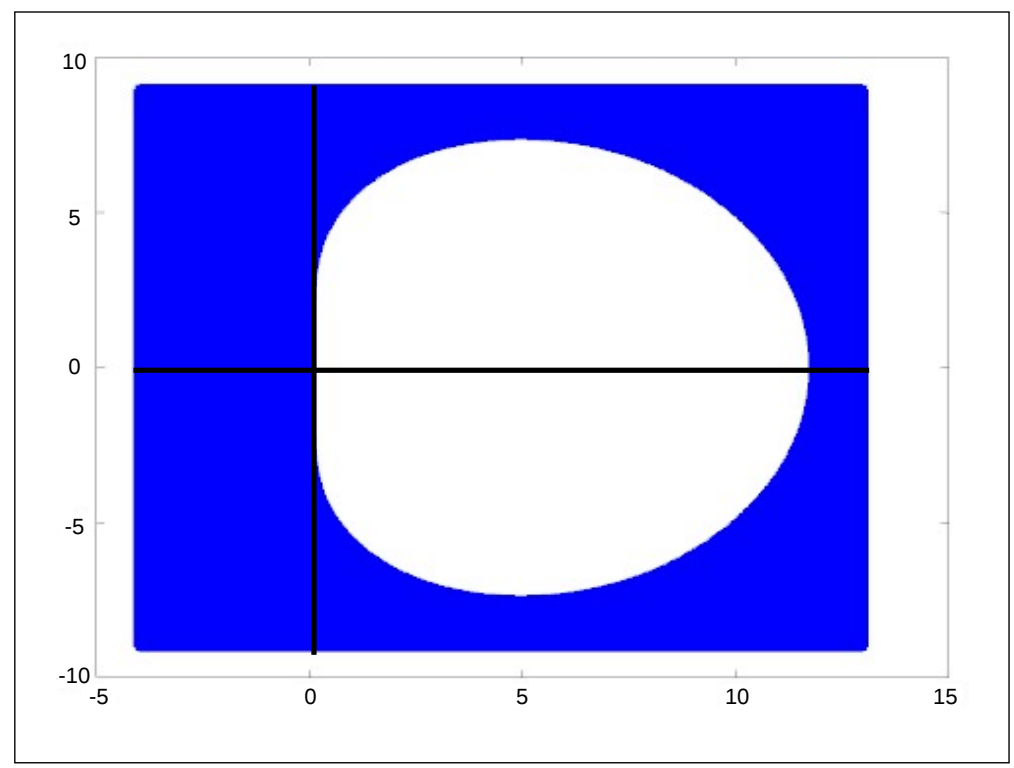

Figura 3.4: Região de estabilidade do Método Radau II de 3 estágios (em azul).

O método Radau II de 3 estágios se mostra adequado para resolução de EDOs rígidas, uma vez que é implícito e possui região de estabilidade ilimitada, tornando possível o uso de estratégias de passo de integração adaptativo. A seguir, mostraremos como se dá a implementação do método Radau II. Para facilitar o entendimento da mudança de variáveis que será realizada, primeiramente vamos reescrever a equação 3.25 da seguinte forma:

$$
\begin{gathered}
\kappa_{i}=x_{0}+h \sum_{j=1}^{s} \alpha_{i j} f\left(t_{0}+\delta_{i} h, \kappa_{j}\right), \quad i=1, \ldots, s, \\
x_{1}=x_{0}+h \sum_{j=1}^{s} \beta_{j} f\left(t_{0}+\delta_{i} h, \kappa_{j}\right) .
\end{gathered}
$$


Introduzindo uma nova variável $z_{i}=\kappa_{i}-x_{0}$ e substituindo na equação 3.39 , temos:

$$
z_{i}=h \sum_{j=1}^{s} \alpha_{i j} f\left(t_{0}+\delta_{i} h, z_{j}+x_{0}\right)
$$

Se soubermos os valores para cada $z_{i}, i=1, \ldots, s$, então a equação 3.40 se torna explícita para $x_{1}$. Seja $A=\left(\alpha_{i j}\right)$, então podemos escrever 3.41 do seguinte modo:

$$
\left[\begin{array}{c}
z_{1} \\
\vdots \\
z_{s}
\end{array}\right]=A\left[\begin{array}{c}
h f\left(t_{0}+\delta_{1} h, x_{0}+z_{1}\right) \\
\vdots \\
h f\left(t_{0}+\delta_{s} h, x_{0}+z_{s}\right)
\end{array}\right]
$$

Assim, é possível reescrevermos também 3.40 como:

$$
x_{1}=x_{0}+\sum_{i=1}^{s} d_{i} z_{i}
$$

onde $\left(d_{1}, \ldots, d_{s}\right)=\left(\beta_{1}, \ldots, \beta_{s}\right) A^{-1}$. Calculando $\beta^{T} A^{-1}$ para o método Radau II temos $\beta^{T} A^{-1}=(0,0,1)$, de onde segue que $d=(0,0,1)$.

O método de Newton-Raphson aplicado ao sistema 3.41 precisa calcular, para cada iteração, a solução de um sistema linear com a matriz:

$$
\left[\begin{array}{ccc}
I-h \alpha_{11} \frac{\partial}{\partial x} f\left(t_{0}+\delta_{1} h, x_{0}+z_{1}\right) & \ldots & -h \alpha_{1 s} \frac{\partial}{\partial x} f\left(t_{0}+\delta_{s} h, x_{0}+z_{s}\right) \\
\vdots & \ddots & \vdots \\
-h \alpha_{s 1} \frac{\partial}{\partial x} f\left(t_{0}+\delta_{1} h, x_{0}+z_{1}\right) & \ldots & I-h \alpha_{s s} \frac{\partial}{\partial x} f\left(t_{0}+\delta_{s} h, x_{0}+z_{s}\right)
\end{array}\right]
$$

Para simplificarmos isto, substituimos todas as Jacobianas $\frac{\partial}{\partial x} f\left(t_{0}+\delta_{i} h, x_{0}+z_{i}\right)$ por uma aproximação $J=\frac{\partial}{\partial x} f\left(t_{0}, x_{0}\right)$. Então, as iterações de Newton-Raphson para a equação 3.41 ficam:

$$
z^{[k+1]}=z^{[k]}-\frac{\left[-z^{[k]}+h(A \otimes I) F\left(z^{[k]}\right)\right]}{-I+h(A \otimes J)}=z^{[k]}+\frac{\left[-z^{[k]}+h(A \otimes I) F\left(z^{[k]}\right)\right]}{I-h(A \otimes J)} .
$$

E deste modo:

$$
\begin{gathered}
\Delta z^{[k]}=z^{[k+1]}-z^{[k]}=\frac{\left[-z^{[k]}+h(A \otimes I) F\left(z^{[k]}\right)\right]}{I-h(A \otimes J)} . \\
\Rightarrow(I-h(A \otimes J)) \triangle z^{[k]}=-z^{[k]}+h(A \otimes I) F\left(z^{[k]}\right) .
\end{gathered}
$$

Nas equações anteriores, $z^{[k]}=\left(z_{1}^{[k]}, \ldots, z_{s}^{[k]}\right)$ é a $k$-ésima aproximação para a solução do sistema e $\triangle z^{[k]}=\left(\triangle z_{1}^{[k]}, \ldots, \triangle z_{s}^{[k]}\right)$ são os incrementos. Além disso, $F\left(z^{[k]}\right)$ é uma 
abreviatura para:

$$
F\left(z^{[k]}\right)=\left(f\left(t_{0}+\delta_{1} h, x_{0}+z_{1}^{[k]}\right), \ldots, f\left(t_{0}+\delta_{s} h, x_{0}+z_{s}^{[k]}\right)\right)^{T} .
$$

Cada iteração requer $s$ avaliações de $f(t, x)$ e a solução de um sistema linear de dimensão $d s$, onde $d$ é a dimensão de $x$ e $s$ o número de estágios do método. Como a matriz $(I-h A J)$ é a mesma para todas as iterações, a sua decomposição LU é realizada somente uma vez e armazenada em memória.

A implementação realizada para este trabalho utiliza como chute inicial para o método iterativo de Newton $z_{i}^{0}=0, i=1, \ldots, s$. Além disso, o critério de parada para o método de Newton depende da precisão desejada e do número máximo de iterações do método $k_{\max }$, tomado como 7, uma vez que testes realizados na literatura (Hairer e Wanner, 1996) para diferentes valores mostraram que o método usualmente converge com um número de iterações menor do que este.

Como vimos anteriormente, uma das vantagens dos métodos A-estáveis está na possibilidade do uso de passo de integração adaptativo. Apresentamos aqui duas maneiras distintas para determinar o tamanho do passo de integração do método Radau II de $s$ estágios. Nosso método considera como novo tamanho do passo o mínimo entre os valores encontrados por cada uma das estratégias. A primeira estratégia faz uso de fórmulas embutidas para cálculo do passo e a segunda leva em conta também informações sobre os dois últimos passos utilizados pelo método.

A estratégia que considera fórmulas embutidas calcula uma aproximação $\hat{x}_{1}$ com um método Radau de menor ordem a partir dos últimos $\kappa_{i}, i=1, \ldots, s$ utilizados pelo método Radau II de $s$ estágios. Tal aproximação é dada por:

$$
\hat{x}_{1}=x_{0}+h\left(\hat{\beta}_{0} f\left(t_{0}, x_{0}\right)+\sum_{i=1}^{s} \hat{\beta}_{i} f\left(t_{0}+\delta_{i} h, \kappa_{i}\right)\right),
$$

onde $\hat{\beta}_{0}=\hat{\gamma}^{-1}$, sendo $\hat{\gamma}$ o autovalor real da matriz $A^{-1}$, que foi anteriormente definida como a inversa de $A=\left(\alpha_{i j}\right)$. Desta forma, o erro é calculado pela seguinte equação:

$$
\operatorname{err}=\left\|\left(I-h \hat{\beta}_{0} J\right)^{-1}\left(\hat{x}_{1}-x_{1}\right)\right\|
$$

De um modo geral, o tamanho do novo passo de integração depende do erro calculado na equação 3.50, do tamanho do último passo utilizado $\left(h_{\text {old }}\right)$, do número máximo de iterações considerado para o método de Newton $\left(k_{\max }\right)$ e do número de iterações realizadas pelo método de Newton na última resolução do sistema linear $\left(k_{N e w t}\right)$ :

$$
h_{\text {new }}^{a}=0,9\left(\frac{2 k_{\text {max }}+1}{2 k_{\text {max }}+k_{\text {Newt }}}\right) h_{\text {old }}\left(\frac{1}{\text { err }}\right)^{\frac{1}{s+1}} .
$$


Na segunda estratégia, o novo passo é calculado de maneira semelhante à primeira, porém considera também os dois últimos passos utilizados e os erros cometidos pelas fórmulas embutidas nas duas últimas iterações do método. A equação 3.52 mostra o cálculo realizado nesta estratégia.

$$
h_{\text {new }}^{b}=0,9\left(\frac{2 k_{\text {max }}+1}{2 k_{\text {max }}+k_{\text {Newt }}}\right) h_{\text {old }}\left(\frac{1}{e r r}\right)^{\frac{1}{s+1}} \frac{h_{\text {old }}}{h_{\text {old }-1}}\left(\frac{e r r_{n}}{e r r_{n-1}}\right)^{\frac{1}{s+1}} .
$$

Demonstrações mais detalhadas sobre as duas estratégias de controle de passo podem ser encontradas em Hairer e Wanner (1996) e Pessanha et al. (2005).

Como vimos nesta subsessão, os métodos de passo único do tipo Runge-Kutta baseados nas fórmulas de quadratura de Radau constituem-se em uma técnica adequada de resolução de problemas rígidos, tendo em vista a sua A-estabilidade e a possibilidade de possuírem alta ordem de convergência. Porém, o estudo de métodos linearmente implícitos A-estáveis também merece destaque, tendo em vista a sua facilidade de implementação e consequente redução de custos computacionais. A próxima subsessão trata sobre os métodos linearmente implícitos propostos por Rosenbrock.

\subsubsection{Métodos de Rosenbrock}

Os métodos de Rosenbrock são métodos de Runge-Kutta semi-implícitos que tem como ideia principal a linearização de métodos Runge-Kutta implícitos. Eles são métodos de passo único que servem como uma alternativa para resolver equações implícitas que são resolvidas normalmente por processos iterativos. A ideia é resolver uma sequência de sistemas lineares em vez de resolver sistemas não lineares, o que facilita a implementação do algoritmo.

Para a definição de um método de Rosenbrock, vamos considerar um sistema autônomo de Equações Diferenciais Ordinárias do tipo 3.53, uma vez que podemos reescrever os sistemas não-autônomos em sistemas autônomos fazendo uma simples mudança de variáveis.

$$
x^{\prime}(t)=f(x(t)), \quad x\left(t_{0}\right)=x_{0},
$$

$\operatorname{com} x(t) \in \mathbb{R}^{d}, t \in\left[t_{0},+\infty\left[\right.\right.$ e $f: \mathbb{R}^{d} \longrightarrow \mathbb{R}^{d}$

Definição 3.8. Dado um sistema autônomo de Equações Diferenciais Ordinárias do tipo 3.53, um método de Rosenbrock de s-estágios é dado pelas fórmulas:

$$
\kappa_{i}=h f\left(x_{0}+\sum_{j=1}^{i-1} \alpha_{i j} \kappa_{j}\right)+h J \sum_{j=1}^{i} \gamma_{i j} \kappa_{j}, \quad i=1, \ldots, s, \quad x_{1}=x_{0}+\sum_{j=1}^{s} \beta_{j} \kappa_{j}
$$

onde $\alpha_{i j}, \gamma_{i j}$ e $\beta_{j}$ são coeficientes determinados de acordo com a ordem de consistência e estabilidade desejadas, $h$ é o passo de integração e $J=f^{\prime}\left(x_{0}\right)$ é a matriz Jacobiana do sistema 3.53. 
Observe que cada estágio do método 3.54 consiste em resolver um sistema linear de equações com desconhecidos $\kappa_{i}$ e com a matriz $I-h \gamma_{i i} J$. Além disso, se tivermos $\gamma_{11}=$ $\ldots, \gamma_{s s}=\gamma \in \mathbb{R}$ precisaremos calcular apenas uma vez por passo a decomposição LU da matriz envolvida, facilitando a implementação do método e reduzindo o tempo de resolução do sistema. Desta forma, vamos considerar métodos que respeitem tal igualdade.

Assim como nos métodos de Radau II, os coeficientes dos métodos de Rosenbrock devem satisfazer determinadas equações que garantem a ordem de convergência do método. Por exemplo, para o caso de um método Rosenbrock de ordem 3, as seguintes equações devem ser satisfeitas:

$$
\begin{gathered}
\sum_{j=1}^{s} \beta_{j}=1, \\
\sum_{j, k=1}^{s} \beta_{j}\left(\alpha_{j k}+\gamma_{j k}\right)=1 / 2, \\
\sum_{j, k, l=1}^{s} \beta_{j} \alpha_{j k} \alpha_{j l}=1 / 3, \\
\sum_{j, k, l=1}^{s} \beta_{j}\left(\alpha_{j k}+\gamma_{j k}\right)\left(\alpha_{k l}+\gamma_{k l}\right)=1 / 6 .
\end{gathered}
$$

A região de estabilidade do método de Rosenbrock também é determinada em função da aplicação da equação teste 3.20 na equação que define o método 3.54. Desta forma, a função de estabilidade $K(z)$ é encontrada e utilizada para a obtenção da região de estabilidade do método, conforme equação 3.37. A função de estabilidade para o método Rosenbrock de $s$-estágios é:

$$
K(z)=1+z \beta^{T}(I-z \hat{A})^{-1} \mathbb{1}
$$

onde $\beta^{T}=\left(\beta_{1}, \ldots, \beta_{s}\right), I$ é a matriz identidade de dimensão $s, \hat{A}=\left(\alpha_{i j}+\gamma_{i j}\right)_{i, j=1}^{s}$ e $\mathbb{1}$ é o vetor de dimensão $s$ com todas as componentes iguais a 1. Escrevendo a função de estabilidade em função de determinantes de matrizes (Hairer e Wanner, 1996), temos:

$$
K(z)=\frac{\operatorname{det}\left(I-z \hat{A}+z \mathbb{1} \beta^{T}\right)}{\operatorname{det}(I-z \hat{A})}
$$

Para os métodos RK implícitos e semi-implícitos, como é o caso do método Rosenbrock, $K(z)$ é uma função racional cujos polinômios numerador e denominador têm grau $\leq s$. Assim:

$$
K(z)=\frac{P(z)}{Q(z)}
$$

É possível reescrevermos $P(z)$ e $Q(z)$ em função do $\gamma$ escolhido e analisarmos detalhadamente a região de estabilidade do método de Rosenbrock, na qual $|K(z)| \leq 1$. A Tabela 3.4, construída com base na análise detalhada realizada por Hairer e Wanner (1996) 
e Sandu et al. (1997), mostra para $s=1, \ldots, 5$ quais valores de $\gamma$ fazem com que a função de estabilidade $K(z)$ torne o método A-estável com ordem de convergência $p$.

\begin{tabular}{lll}
\hline$s$ & $p \geq s-1$ & $p=s$ \\
\hline 1 & - & $\gamma=1$ \\
2 & $(2-\sqrt{2}) / 2 \leq \gamma \leq(2+\sqrt{2}) / 2$ & $\gamma=(2 \pm \sqrt{2}) / 2$ \\
3 & $0,18042531 \leq \gamma \leq 2,18560010$ & $\gamma=0,43586652$ \\
4 & $0,22364780 \leq \gamma \leq 0,57281606$ & $\gamma=0,57281606$ \\
5 & $0,24799464 \leq \gamma \leq 0,67604239$ & $\gamma=0,27805384$ \\
\hline
\end{tabular}

Tabela 3.4: A-estabilidade do Método Rosenbrock de s estágios e ordem p em função do $\gamma$ escolhido.

Desta forma, verificamos que é possível a construção de métodos RK linearmente implícitos do tipo Rosenbrock que sejam A-estáveis para altas ordens de convergência. Estas características tornam os métodos de Rosenbrock adequados para o cálculo da solução de problemas rígidos de EDOs.

A implementação dos métodos Rosenbrock pode ser facilitada quando utilizamos uma mudança de variáveis. A multiplicação matriz-vetor $J \sum \gamma_{i j} \kappa_{j}$ que aparece em cada estágio do método pode ser evitada se considerarmos a seguinte mudança de variáveis proposta por Hairer e Wanner (1996):

$$
u_{i}=\sum_{j=1}^{i} \gamma_{i j} \kappa_{j}, \quad i=1, \ldots, s .
$$

Deste modo, se $\gamma_{i i} \neq 0 \forall i$, a matriz definida por $\Gamma=\left(\gamma_{i j}\right)$ é invertível e cada $\kappa_{i}$ pode ser obtido a partir de $u_{i}$ da seguinte forma:

$$
\kappa_{i}=\frac{1}{\gamma_{i i}} u_{i}-\sum_{j=1}^{i} c_{i j} u_{j}, \quad i=1, \ldots, s
$$

onde $c_{i j}$ são os elementos da matriz $C=\operatorname{diag}\left(\gamma_{11}^{-1}, \ldots, \gamma_{s s}^{-1}\right)-\Gamma^{-1}$.

Inserindo estas novas variáveis na equação que define o método 3.54 e fazendo os devidos ajustes matemáticos, podemos reescrever um método Rosenbrock de $s$ estágios da seguinte maneira:

$$
\begin{gathered}
\left(\frac{1}{h \gamma_{i i}} I-J\right) u_{i}=f\left(x_{0}+\sum_{j=1}^{i-1} a_{i j} u_{j}\right)+\sum_{j=1}^{i-1} \frac{c_{i j}}{h} u_{j}, \quad i=1, \ldots, s, \\
x_{1}=x_{0}+\sum_{j=1}^{s} m_{j} u_{j},
\end{gathered}
$$

onde $\left(a_{i j}\right)=\left(\alpha_{i j}\right) \Gamma^{-1}$ e $\left(m_{1}, \ldots, m_{s}\right)=\left(\beta_{1}, \ldots, \beta_{s}\right) \Gamma^{-1}$.

Substituições de variáveis como as descritas anteriormente evitam não somente as multiplicações matriz-vetor mencionadas anteriormente como também inúmeras outras multi- 
plicações inerentes ao método, corroborando para a redução dos custos computacionais. Estas transformações podem ser encontradas também em Wolfbrandt (1977), Kaps e Wanner (1981), Shampine (1982) e Kaps et al. (1985).

Uma vez que os métodos de Rosenbrock são métodos de passo único A-estáveis podemos facilmente empregar estratégias de controle do tamanho do passo de integração. Assim como no método Radau II, o controle do passo é baseado em fórmulas embutidas que usam os valores $\kappa_{i}$ já calculados da seguinte forma:

$$
\hat{x}_{1}=x_{0}+\sum_{i=1}^{s} \hat{\beta}_{i} \kappa_{i}
$$

onde os valores dos pesos $\hat{\beta}_{i}$ são escolhidos de modo que a ordem de convergência de $\hat{x}_{1}$ seja $\hat{p}=p-1$, assumindo que o método utilizado para o cálculo da aproximação $x_{1}$ seja de ordem $p$. Nestes casos dizemos que o método Rosenbrock é de ordem $p(\hat{p})$.

O erro local é estimado de acordo com a diferença absoluta entre as aproximações $x_{1}$ e $\hat{x}_{1}$. Assim, err $=\left\|x_{1}-\hat{x}_{1}\right\|$ e o passo de integração é aceito se err $<1$, caso contrário é rejeitado e recalculado. O novo tamanho de passo, que é calculado a cada iteração, é estimado por:

$$
h_{\text {new }}=h \cdot \min \left(f a c_{\text {max }}, \max \left(f a c_{\text {min }}, \frac{0,9}{(e r r)^{\frac{1}{p+1}}}\right)\right) \text {, }
$$

onde $f a c_{\max }$ e $f a c_{\min }$ são limitantes para o tamanho do passo determinados de acordo com a ordem do método (Hairer e Wanner, 1996).

O método Rosenbrock implementado para este trabalho é de 4 estágios e ordem 3. Utilizamos as mudanças de variáveis descritas acima para a implementação e um método embutido de ordem 2 para o controle do passo de integração. Considerando $\gamma=\frac{1}{2}$, utilizamos os valores propostos por Sandu et al. (1997) para os demais coeficientes do método, quais sejam:

$$
\begin{gathered}
\left(\alpha_{i j}\right)=\left(\begin{array}{cccc}
0 & & & \\
0 & 0 & & \\
1 & 0 & 0 & \\
\frac{3}{4} & -\frac{1}{4} & \frac{1}{2} & 0
\end{array}\right), \quad\left(\gamma_{i j}\right)=\left(\begin{array}{cccc}
\frac{1}{2} & & & \\
1 & \frac{1}{2} & & \\
-\frac{1}{4} & -\frac{1}{4} & \frac{1}{2} & \\
\frac{1}{12} & \frac{1}{12} & -\frac{2}{3} & \frac{1}{2}
\end{array}\right), \\
\left(\beta_{i}\right)=\left(\begin{array}{lllll}
\frac{5}{6} & -\frac{1}{6} & -\frac{1}{6} & \frac{1}{2}
\end{array}\right), \quad\left(\hat{\beta}_{i}\right)=\left(\begin{array}{cccc}
\frac{3}{4} & -\frac{1}{4} & \frac{1}{2} & 0
\end{array}\right) .
\end{gathered}
$$

Desta forma, a matriz inversa de $\Gamma=\left(\gamma_{i j}\right)$ é dada por:

$$
\Gamma^{-1}=\left(\begin{array}{cccc}
2 & 0 & 0 & 0 \\
-4 & 2 & 0 & 0 \\
-1 & 1 & 2 & 0 \\
-1 & 1 & \frac{8}{3} & 2
\end{array}\right)
$$


Portanto, os novos coeficientes do método são dados por:

$$
\begin{gathered}
C=\operatorname{diag}\left(\gamma_{11}^{-1}, \ldots, \gamma_{44}^{-1}\right)-\Gamma=\left(\begin{array}{cccc}
0 & 0 & 0 & 0 \\
4 & 0 & 0 & 0 \\
1 & -1 & 0 & 0 \\
1 & -1 & -\frac{8}{3} & 0
\end{array}\right) \\
\left(a_{i j}\right)=\left(\alpha_{i j}\right) \Gamma^{-1}=\left(\begin{array}{cccc}
0 & 0 & 0 & 0 \\
0 & 0 & 0 & 0 \\
2 & 0 & 0 & 0 \\
2 & 0 & 1 & 0
\end{array}\right) \\
\left(m_{1}, m_{2}, m_{3}, m_{4}\right)=\left(\beta_{1}, \beta_{2}, \beta_{3}, \beta_{4}\right) \Gamma^{-1}=\left(\begin{array}{llll}
2 & 0 & 1 & 1
\end{array}\right), \\
\left(\hat{m}_{1}, \hat{m}_{2}, \hat{m}_{3}, \hat{m}_{4}\right)=\left(\hat{\beta}_{1}, \hat{\beta}_{2}, \hat{\beta}_{3}, \hat{\beta}_{4}\right) \Gamma^{-1}=\left(\begin{array}{llll}
2 & 0 & 1 & 0
\end{array}\right) .
\end{gathered}
$$

Assim, podemos escrever o método Rosenbrock de 4 estágios e ordem 3(2) da seguinte forma:

$$
\begin{aligned}
& x_{0}=x\left(t_{0}\right) \\
& \hat{x}_{1}=x_{0}+2 u_{1}+u_{3}, \\
& x_{1}=x_{0}+2 u_{1}+u_{3}+u_{4}
\end{aligned}
$$

onde $u_{1}, u_{2}, u_{3}$ e $u_{4}$ são as soluções dos seguintes sistemas lineares:

$$
\begin{gathered}
\left(\frac{2}{h} I-J\right) u_{1}=f\left(x_{0}\right), \\
\left(\frac{2}{h} I-J\right) u_{2}=f\left(x_{0}\right)+\frac{4}{h} u_{1}, \\
\left(\frac{2}{h} I-J\right) u_{3}=f\left(x_{0}+2 u_{1}\right)+\frac{1}{h} u_{1}-\frac{1}{h} u_{2}, \\
\left(\frac{2}{h} I-J\right) u_{4}=f\left(x_{0}+2 u_{1}+u_{3}\right)+\frac{1}{h} u_{1}-\frac{1}{h} u_{2}-\frac{8}{3} u_{3},
\end{gathered}
$$

Para o método Rosenbrock de 4-estágios e ordem 3(2) aqui implementado, os fatores $f a c_{\max }$ e $f a c_{\min }$ utilizados no controle do tamanho do passo de integração foram respectivamente 10 e 0,1 (Sandu et al., 1997).

Substituindo na equação 3.59 os valores de $\beta_{i}, \alpha_{i j}$ e $\gamma_{i j}$ utilizados para a implementação do método Rosenbrock deste trabalho, segue que a função de estabilidade do método Rosenbrock de 4 estágios e ordem 3(2) é dada por:

$$
K(z)=\frac{8\left(z^{3}-6 z+6\right)}{3(z-2)^{4}} .
$$

A região de estabilidade do método Rosenbrock implementado neste trabalho, construída 
a partir da sua função de estabilidade determinada na equação 3.80, está representada em azul na Figura 3.5. Observe que a região comprende todo o semiplano esquerdo, comprovando a A-estabilidade do método.

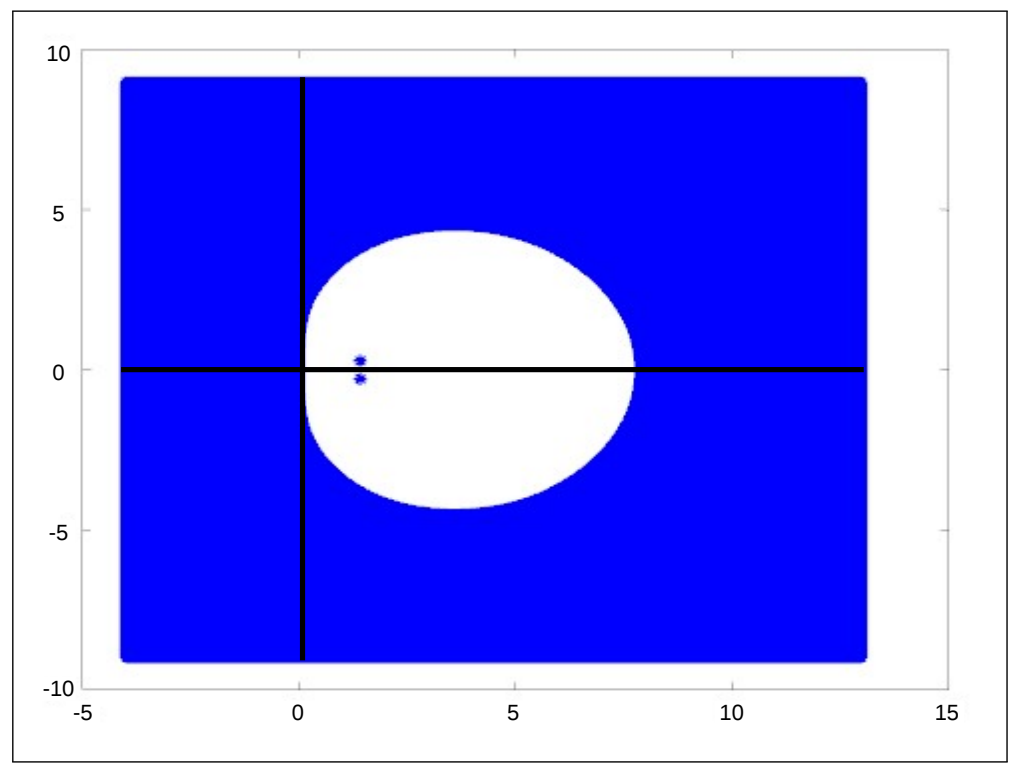

Figura 3.5: Região de estabilidade do Método Rosenbrock de 4 estágios (em azul).

Vimos que os dois métodos de passo único estudados neste capítulo são adequados para a resolução de problemas rígidos de Equações Diferenciais Ordinárias, uma vez que possuem região de estabilidade ilimitada e possibilitam o uso de estratégias de controle do passo de integração sem que a ordem de convergência do método seja comprometida. O próximo capítulo apresenta a resolução dos problemas rígidos de decaimento radioativo que motivaram nosso estudo utilizando os métodos Radau II de 3 estágios e ordem 5 e Rosenbrock de 4 estágios e ordem $3(2)$. 
34 SOLUÇÕES PARA OS PROBLEMAS RÍGIDOS DE EQUAÇÕES DIFERENCIAIS ORDINÁRIAS 


\section{Capítulo 4}

\section{Simulações Numéricas dos Problemas de Decaimento Radiotaivo}

Como vimos no capítulo anterior, os métodos implementados para as simulações de problemas rígidos que serviram como motivação para este trabalho foram os seguintes: método Radau II de 3 estágios e ordem 5 e método Rosenbrock de 4 estágios e ordem 3(2). Este capítulo mostra a aplicação dos métodos implementados para resolução de uma cadeia de decaimento natural e de uma cadeia artificial. Mostraremos através de um exemplo que é possível determinar a solução tanto para o passado como para o futuro.

Em cada aplicação faremos uma comparação entre os métodos com relação à precisão alcançada e ao número de passos necessários para tal.

Em função da dificuldade intrínseca na definição do conceito preciso de rigidez, nos valemos das diferentes afirmações realizadas no capítulo 2 com relação ao termo e caracterizamos a rigidez dos problemas considerados neste capítulo quando eles satisfazem pelo menos uma daquelas afirmações.

Os algoritmos foram implementados em Fortran 90 e executados em uma máquina com processador Intel@ Core $^{T M}$ i5-2450M e sistema Ubuntu 14.04 LTS 32-bit.

\subsection{Cadeia Natural de Decaimento do Urânio-238}

Como primeiro exemplo de aplicação vamos considerar a cadeia de decaimento natural do Urânio-238 (Figura 1.2), que configura um problema rígido cuja taxa de rigidez, calculada pela equação 2.14 , é aproximadamente $0,886 \times 10^{21}$.

As taxas de transferência $\lambda_{i}, i=1, \ldots, 14$, que aparecem na Figura 1.2 são as constantes de decaimento de cada elemento e são calculadas em função das suas meias-vidas $\left(T_{(1 / 2)}^{i}\right)$ de acordo com a equação 1.2. A Tabela 4.1 identifica cada radionuclídeo da cadeia do ${ }^{238} \mathrm{U}$ de acordo com a modelagem proposta $x^{\prime}(t)=A x(t)$ e mostra os valores de suas meias-vidas e respectivas constantes de decaimento.

O núcleo do ${ }^{206} \mathrm{~Pb}$ é estável e por isso não decai naturalmente para outro elemento. 


\begin{tabular}{lccc}
\hline Elemento & Variável $x_{i}$ & Meia-Vida $T_{(1 / 2)}^{i}$ & Taxa de Decaimento $\lambda_{i}\left(\mathrm{em} \mathrm{dia}^{-1}\right)$ \\
\hline${ }^{238} \mathrm{U}$ & $x_{1}$ & 4,5 bilhões de anos & $0,422 \mathrm{E}-12$ \\
${ }^{234} \mathrm{Th}$ & $x_{2}$ & 24 dias & $0,288 \mathrm{E}-01$ \\
${ }^{234} \mathrm{~Pa}$ & $x_{3}$ & 1,2 minutos & $0,831 \mathrm{E}+03$ \\
${ }^{234} \mathrm{U}$ & $x_{4}$ & 240000 anos & $0,791 \mathrm{E}-08$ \\
${ }^{230} \mathrm{Th}$ & $x_{5}$ & 77000 anos & $0,246 \mathrm{E}-07$ \\
${ }^{226} \mathrm{Ra}$ & $x_{6}$ & 1600 anos & $0,118 \mathrm{E}-05$ \\
${ }^{222} \mathrm{Rn}$ & $x_{7}$ & 3,8 dias & $0,182 \mathrm{E}+00$ \\
${ }^{218} \mathrm{Po}$ & $x_{8}$ & 3,1 minutos & $0,321 \mathrm{E}+03$ \\
${ }^{214} \mathrm{~Pb}$ & $x_{9}$ & 27 minutos & $0,369 \mathrm{E}+02$ \\
${ }^{214} \mathrm{Bi}$ & $x_{10}$ & 20 minutos & $0,499 \mathrm{E}+02$ \\
${ }^{214} \mathrm{Po}$ & $x_{11}$ & 160 microssegundos & $0,374 \mathrm{E}+09$ \\
${ }^{210} \mathrm{~Pb}$ & $x_{12}$ & 22 anos & $0,863 \mathrm{E}-04$ \\
${ }^{210} \mathrm{Bi}$ & $x_{13}$ & 5 dias & $0,138 \mathrm{E}+00$ \\
${ }^{210} \mathrm{Po}$ & $x_{14}$ & 140 dias & $0,495 \mathrm{E}-02$ \\
\hline
\end{tabular}

Tabela 4.1: Meias-vidas e constantes de decaimento da série de decaimento natural do ${ }^{238} U$ (Kocher, 1981).

Assim, a equação que descreve o seu comportamento pode ser desconsiderada na resolução do sistema que modela o problema. Portanto, vamos considerar a matriz $A \operatorname{dos}$ coeficientes de dimensão 14, compreendendo os elementos entre o ${ }^{238} \mathrm{U}$ e o ${ }^{210} \mathrm{Po}$.

Note que enquanto a constante de decaimento do Urânio-238 é da ordem de $10^{-12}$, a constante de decaimento do Polônio-214 é da ordem de $10^{9}$. Esta grande diferença entre as ordens de grandeza das taxas se traduz em uma matriz $A$ dos coeficientes quase singular cujo determinante tem valor aproximado de $0,8735 \times 10^{-26}$.

A solução numérica para o problema proposto foi calculada considerando que no instante inicial $t_{0}=0$ existe somente $10^{4}$ unidades de ${ }^{238} \mathrm{U}$ e o inventário dos demais elementos da série é nulo. Ou seja, $x_{1}(0)=10000$ e $x_{i}(0)=0, i=2, \ldots, 14$. Avaliamos o desempenho dos métodos para 10 bilhões de dias a partir do instante inicial e exigindo uma precisão pré-definida de $10^{-4}$.

Para obtermos uma solução estável e consistente com a precisão desejada dentro do intervalo considerado utilizando o método de passo único fixo RK 4-4 estimamos que o tamanho do passo de integração deve ser da ordem de $10^{-15}$, implicando o cálculo de aproximadamente 6, $667 \times 10^{25}$ iterações do método (Loch et al., 2013b). Usando este valor como passo inicial para os métodos Radau II e Rosenbrock implementados, é possível encontrarmos soluções robustas para o problema proposto com um número de iterações cerca de $10^{20}$ vezes menor do que o método RK-44. O método Radau II calculou a solução com a precisão desejada realizando 230456 iterações e o método Rosenbrock calculou 237613 iterações. Em estudo realizado por Loch et al. (2013a) foi verificado que quanto mais próximo do final da cadeia estiver posicionado o elemento que possui a taxa de transferência com ordem de 
grandeza mais discrepante em relação à ordem dos demais, maior será o número de iterações necessárias para o método de Rosenbrock obter soluções convergentes e consistentes, já que para manter a estabilidade do método, o tamanho do passo de integração é reduzido. Aqui, verificou-se comportamento semelhante para o método Radau II implementado.

As soluções numéricas dadas pelos algoritmos de Radau II e Rosenbrock, após 10 bilhões de dias, são apresentadas na Tabela 4.2, onde é possível observar a coerência entre as soluções. Ambos os métodos calcularam a solução do problema com um número de iterações da mesma ordem de grandeza e em poucos segundos de execução. As Figuras 4.1 à 4.14 mostram a solução numérica do problema calculada pelo método de Rosenbrock para cada um dos elementos separadamente.

\begin{tabular}{lcc}
\hline Elemento & Rosenbrock (237.613 passos) & Radau II $(230.456$ passos $)$ \\
\hline${ }^{238} \mathrm{U}$ & $0,9957 \mathrm{E}+04$ & $0,9957 \mathrm{E}+04$ \\
${ }^{234} \mathrm{Th}$ & $0,1455 \mathrm{E}-06$ & $0,1455 \mathrm{E}-06$ \\
${ }^{234} \mathrm{~Pa}$ & $0,5052 \mathrm{E}-11$ & $0,5052 \mathrm{E}-11$ \\
${ }^{234} \mathrm{U}$ & $0,5311 \mathrm{E}+00$ & $0,5311 \mathrm{E}+00$ \\
${ }^{230} \mathrm{Th}$ & $0,1704 \mathrm{E}+00$ & $0,1704 \mathrm{E}+00$ \\
${ }^{226} \mathrm{Ra}$ & $0,3540 \mathrm{E}-02$ & $0,3540 \mathrm{E}-02$ \\
${ }^{222} \mathrm{Rn}$ & $0,2303 \mathrm{E}-07$ & $0,2303 \mathrm{E}-07$ \\
${ }^{218} \mathrm{Po}$ & $0,1305 \mathrm{E}-10$ & $0,1305 \mathrm{E}-10$ \\
${ }^{214} \mathrm{~Pb}$ & $0,1136 \mathrm{E}-09$ & $0,1136 \mathrm{E}-09$ \\
${ }^{214} \mathrm{Bi}$ & $0,8420 \mathrm{E}-10$ & $0,8420 \mathrm{E}-10$ \\
${ }^{214} \mathrm{Po}$ & $0,1122 \mathrm{E}-16$ & $0,1123 \mathrm{E}-16$ \\
${ }^{210} \mathrm{~Pb}$ & $0,4868 \mathrm{E}-04$ & $0,4868 \mathrm{E}-04$ \\
${ }^{210} \mathrm{Bi}$ & $0,3031 \mathrm{E}-07$ & $0,3031 \mathrm{E}-07$ \\
${ }^{210} \mathrm{Po}$ & $0,8488 \mathrm{E}-06$ & $0,8488 \mathrm{E}-06$ \\
\hline
\end{tabular}

Tabela 4.2: Solução após 10 bilhões de dias para a série de decaimento natural do ${ }^{238} \mathrm{U}$.

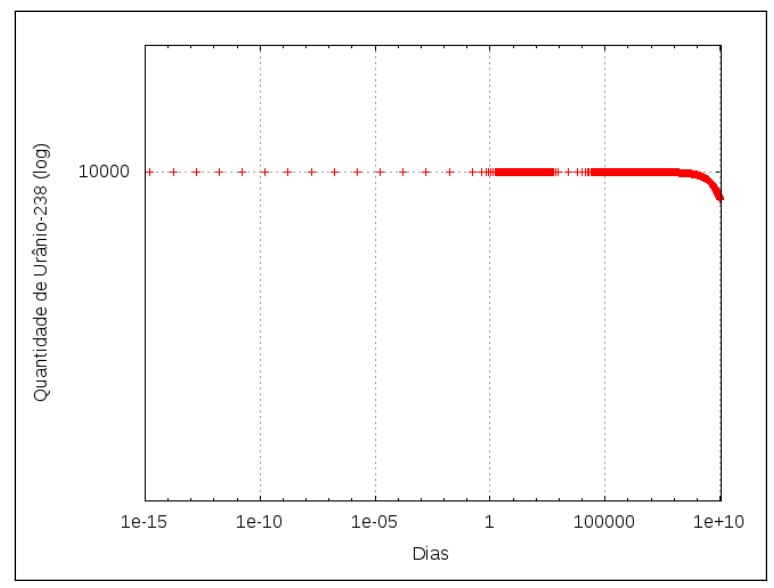

Figura 4.1: Solução para Urânio-238.

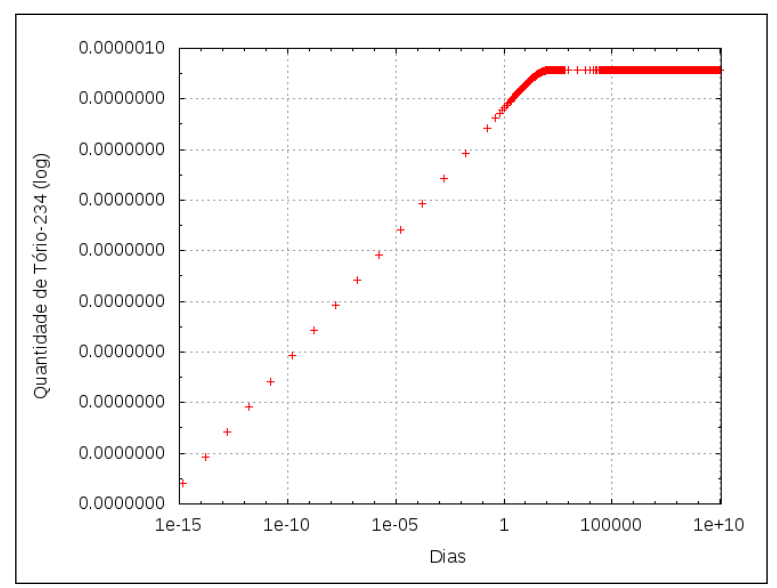

Figura 4.2: Solução para Tório-234. 


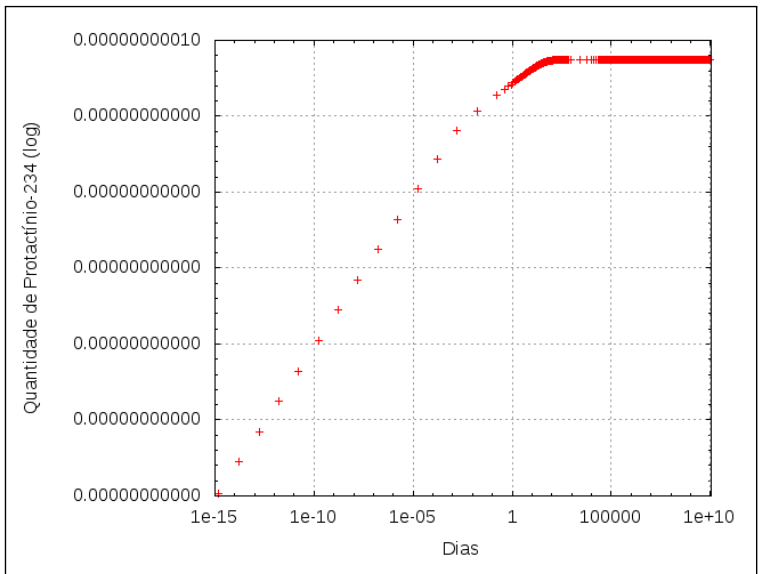

Figura 4.3: Solução para Protactínio-234.

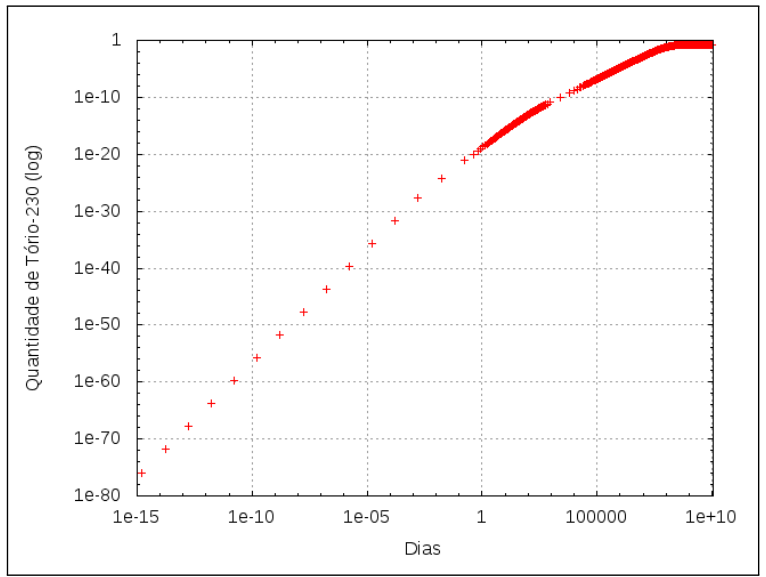

Figura 4.5: Solução para Tório-230.

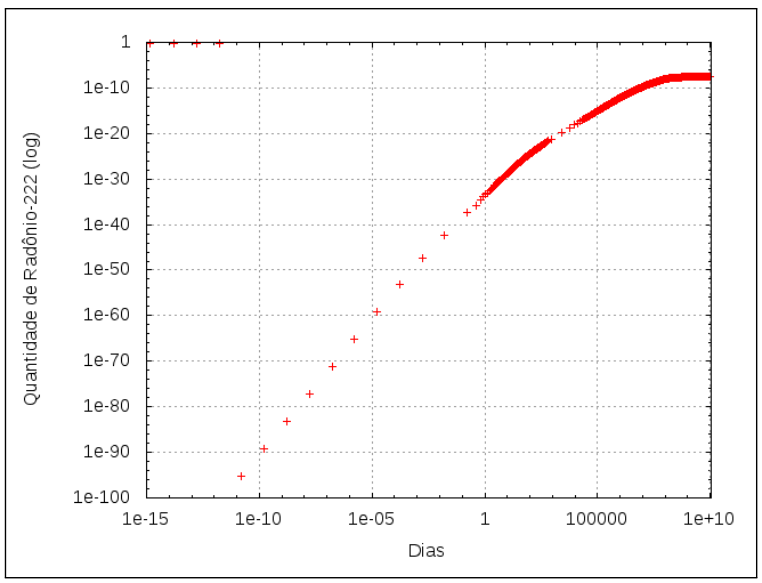

Figura 4.7: Solução para Radônio-222.

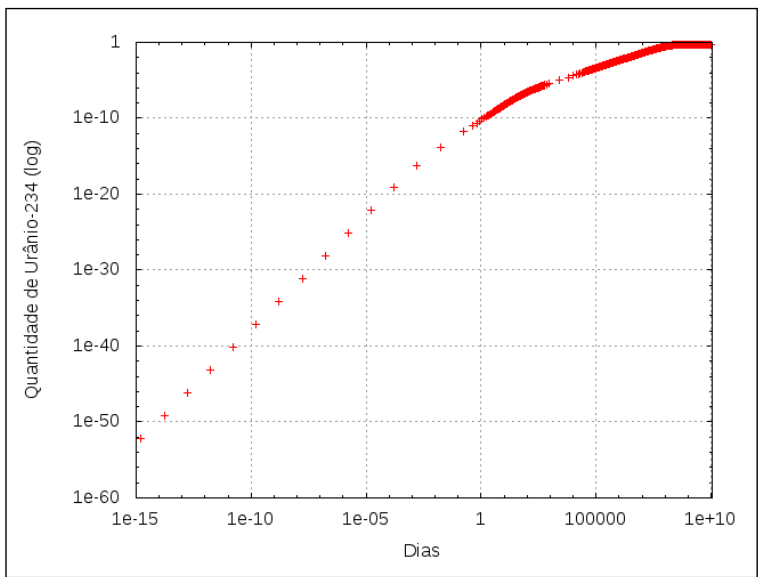

Figura 4.4: Solução para Urânio-234.

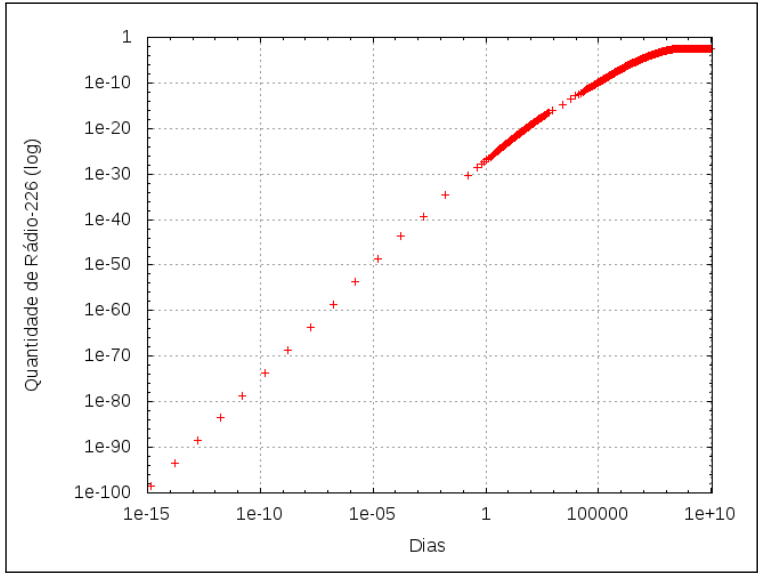

Figura 4.6: Solução para Rádio-226.

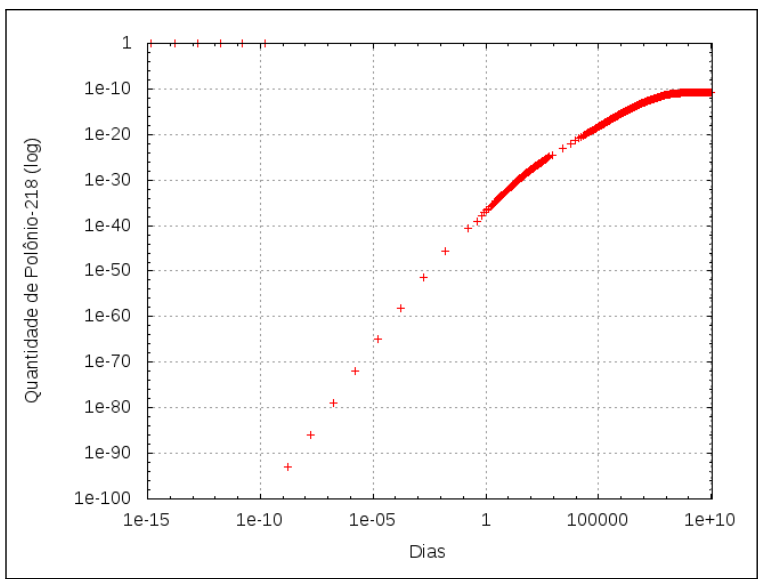

Figura 4.8: Solução para Polônio-218. 


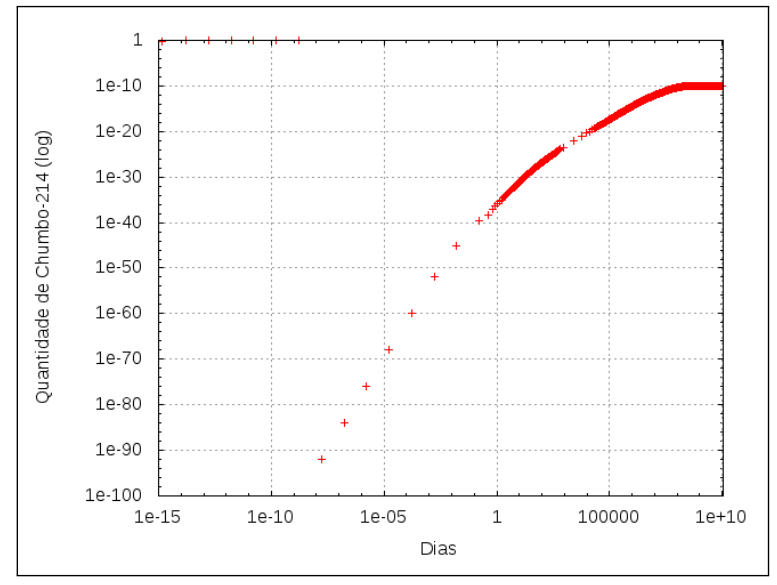

Figura 4.9: Solução para Chumbo-214.

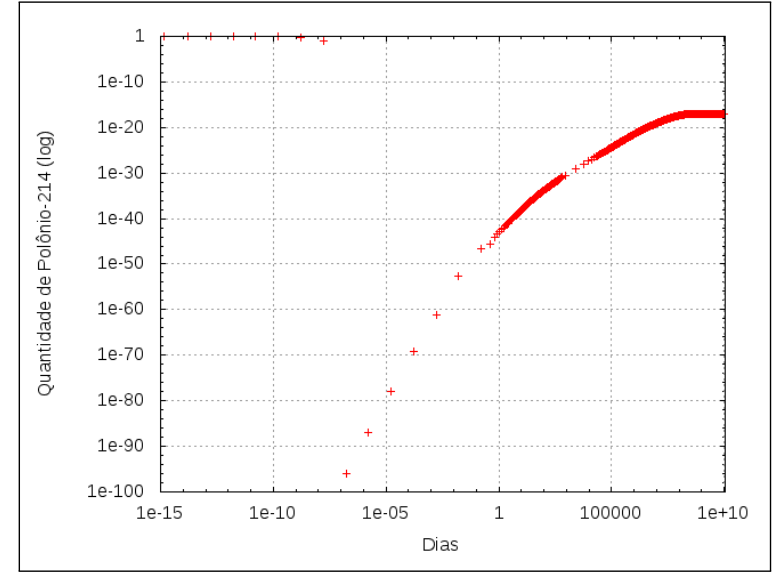

Figura 4.11: Solução para Polônio-214.

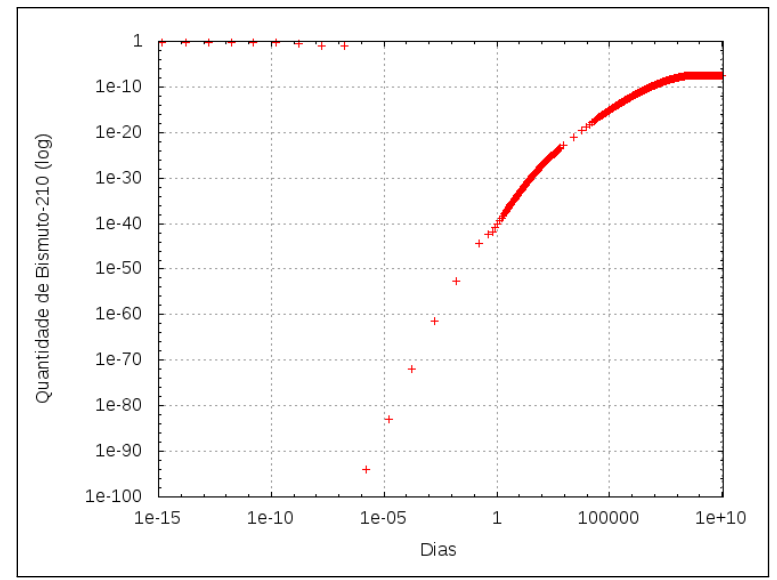

Figura 4.13: Solução para Bismuto-210.

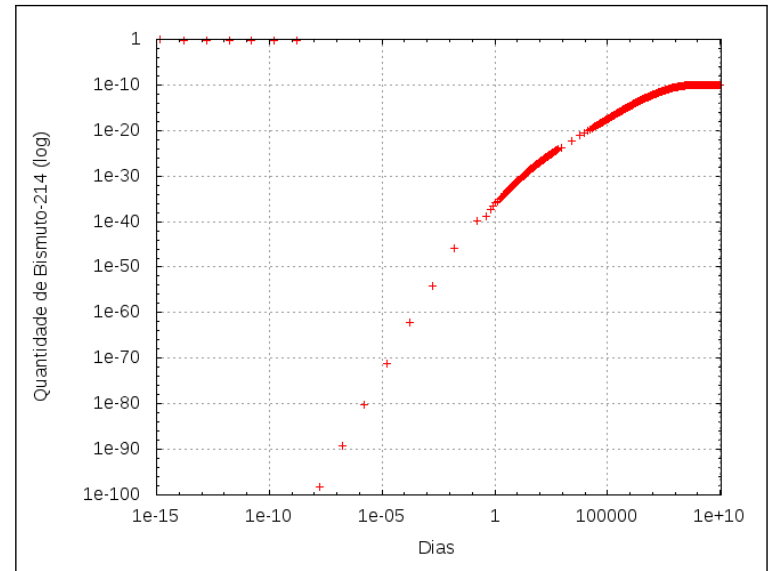

Figura 4.10: Solução para Bismuto-214.

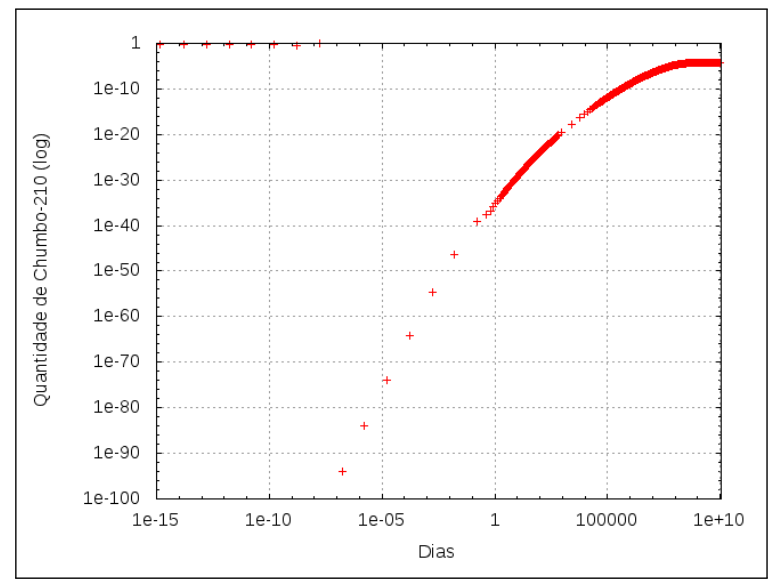

Figura 4.12: Solução para Chumbo-210.

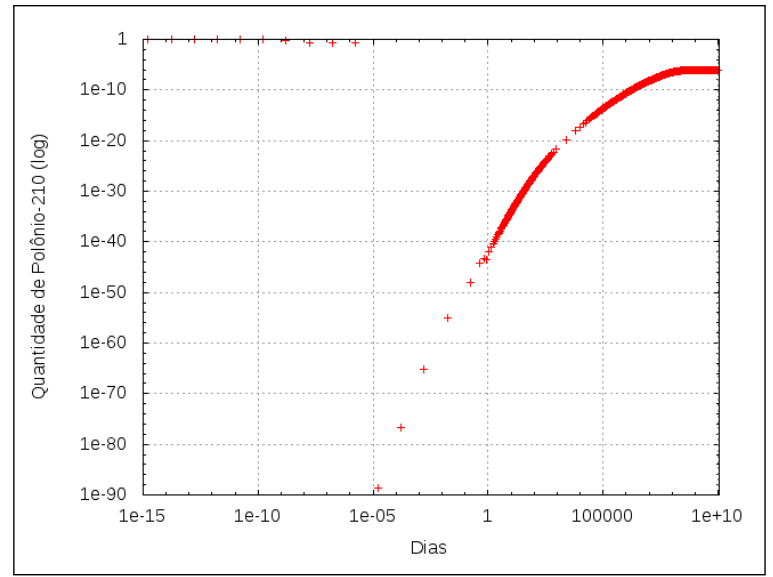

Figura 4.14: Solução para Polônio-210. 


\subsection{Cadeia de Decaimento com Retirada de Elementos}

As quantidades de radioisótopos necessárias para o uso em áreas aplicadas como indústria, agricultura e medicina normalmente são retiradas das cadeias durante o processo de decaimento radioativo. Considerando novamente a cadeia de decaimento natural do Urânio238 (Figura 1.2) podemos citar como exemplo o uso do elemento Radônio-222, um gás nobre utilizado para radioterapia e na composição de cápsulas destinadas ao tratamento do câncer (Zamboni et al., 2011).

Vamos considerar o mesmo problema da sessão anterior assumindo que 10 por cento da quantidade existente de ${ }^{222} \mathrm{Rn}$ é continuamente emanada da amostra durante o processo de decaimento natural da série do ${ }^{238} \mathrm{U}$. As condições iniciais, o período de avaliação de 10 bilhões de dias e a precisão requerida de $10^{-4}$ também são mantidos.

De acordo com a Tabela 4.1, o elemento ${ }^{222} \mathrm{Rn}$ corresponde à variável $x_{7}$, cuja equação para o problema da sessão anterior, sem extração, é dada por:

$$
x_{7}^{\prime}(t)=\lambda_{6} x_{6}(t)-\lambda_{7} x_{7}(t) .
$$

Para o caso em que há extração contínua de 10 por cento da quantidade existente de Radônio-222, a equação 4.1 se modifica para:

$$
x_{7}^{\prime}(t)=\lambda_{6} x_{6}(t)-\lambda_{7} x_{7}(t)-0,1 x_{7}(t)=\lambda_{6} x_{6}(t)-\left(\lambda_{7}+0,1\right) x_{7}(t) .
$$

As soluções encontradas pelos métodos Radau II e Rosenbrock mostraram-se mais uma vez coerentes entre si e são apresentadas na Tabela 4.3.

Comparando as soluções encontradas para o caso em que há extração do Radônio-222 com aquelas encontradas na sessão anterior, onde não há extração de qualquer elemento da cadeia natural do Urânio-238, é possível verificar que o sistema sofre alterações mais significativas na solução para os elementos dispostos após o elemento retirado da cadeia. A Figura 4.15 apresenta a diferença entre a quantidade de Radônio-222 remanescente em cada uma das amostras dos dois casos considerados (com e sem extração). Note que a diferença aumenta no início do período e se mantém constante depois de aproximadamente $10^{9}$ dias. 


\begin{tabular}{lcc}
\hline Elemento & Rosenbrock (237.613 passos) & Radau II (230.456 passos) \\
\hline${ }^{238} \mathrm{U}$ & $0,9957 \mathrm{E}+04$ & $0,9957 \mathrm{E}+04$ \\
${ }^{234} \mathrm{Th}$ & $0,1455 \mathrm{E}-06$ & $0,1455 \mathrm{E}-06$ \\
${ }^{234} \mathrm{~Pa}$ & $0,5052 \mathrm{E}-11$ & $0,5052 \mathrm{E}-11$ \\
${ }^{234} \mathrm{U}$ & $0,5311 \mathrm{E}+00$ & $0,5311 \mathrm{E}+00$ \\
${ }^{230} \mathrm{Th}$ & $0,1704 \mathrm{E}+00$ & $0,1704 \mathrm{E}+00$ \\
${ }^{226} \mathrm{Ra}$ & $0,3540 \mathrm{E}-02$ & $0,3540 \mathrm{E}-02$ \\
${ }^{222} \mathrm{Rn}$ & $0,1488 \mathrm{E}-07$ & $0,1488 \mathrm{E}-07$ \\
${ }^{218} \mathrm{Po}$ & $0,8430 \mathrm{E}-11$ & $0,8430 \mathrm{E}-11$ \\
${ }^{214} \mathrm{~Pb}$ & $0,7342 \mathrm{E}-10$ & $0,7342 \mathrm{E}-10$ \\
${ }^{214} \mathrm{Bi}$ & $0,5439 \mathrm{E}-10$ & $0,5439 \mathrm{E}-10$ \\
${ }^{214} \mathrm{Po}$ & $0,7252 \mathrm{E}-17$ & $0,7251 \mathrm{E}-17$ \\
${ }^{210} \mathrm{~Pb}$ & $0,3144 \mathrm{E}-04$ & $0,3144 \mathrm{E}-04$ \\
${ }^{210} \mathrm{Bi}$ & $0,1958 \mathrm{E}-07$ & $0,1958 \mathrm{E}-07$ \\
${ }^{210} \mathrm{Po}$ & $0,5482 \mathrm{E}-06$ & $0,5482 \mathrm{E}-06$ \\
\hline
\end{tabular}

Tabela 4.3: Solução após 10 bilhões de dias para a série de decaimento natural do ${ }^{238}$ U com extração contínua do ${ }^{222} \mathrm{Rn}$.

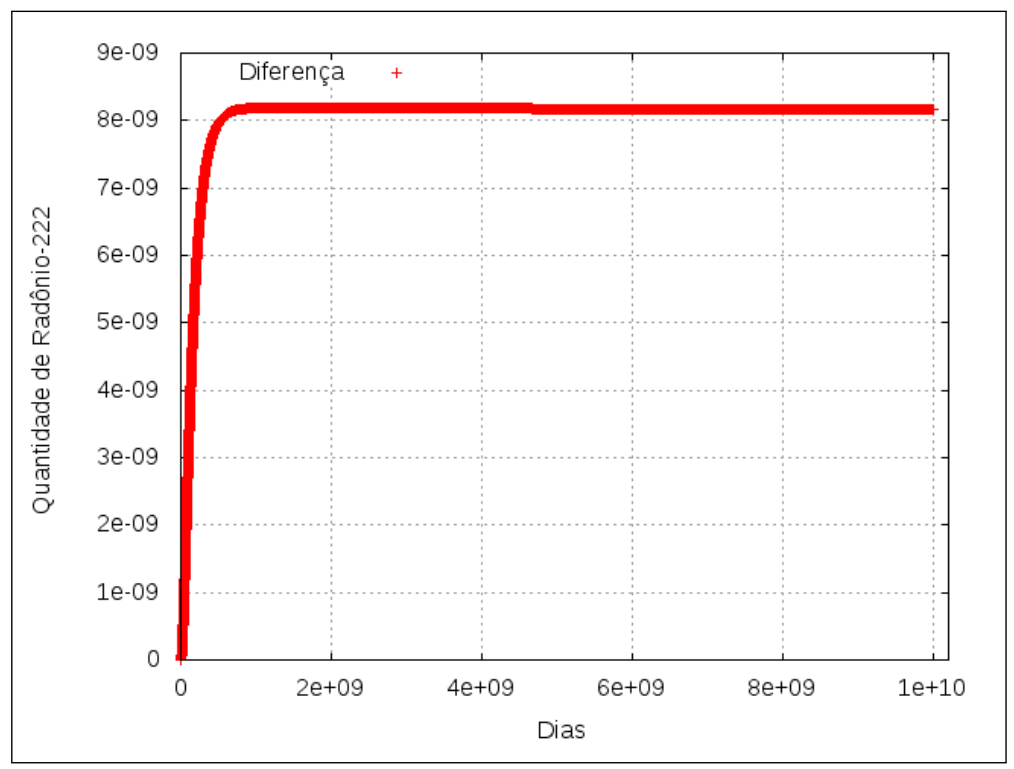

Figura 4.15: Diferença entre a quantidade de ${ }^{222} \mathrm{Rn}$ em cada um dos casos após 10 bilhões de dias. 


\subsection{Inventário Passado e Futuro de uma Cadeia de De- caimento}

O objetivo aqui é recuperar numericamente o inventário inicial de cada elemento de uma cadeia composta por $n$ elementos conhecendo somente o instante $t_{j}$ no qual é verificada a existência de uma quantidade $x_{i}$ do elemento $i(1 \leq i \leq n)$. Isto torna possível a obtenção de uma aproximação numérica para o inventário de todos os radionuclídeos em qualquer instante de tempo $t \in \mathbb{R}$. Ou seja, podemos reconstruir o inventário histórico de cada elemento e determinar a sua quantidade para qualquer período futuro.

Primeiramente, calculamos o inventário de todos os isótopos presentes na amostra no instante $t_{j}$ e a partir destes valores retrocedemos ou evoluímos no tempo utilizando métodos numéricos A-estáveis. Este cálculo inicial é realizado com base na seguinte equação (Loch et al., 2015):

$$
\frac{\lambda_{d} N_{d}}{\lambda_{p} N_{p}}=\frac{f T_{1 / 2}(p)}{T_{1 / 2}(p)-T_{1 / 2}(d)}\left[1-e^{-\left(\lambda_{d}-\lambda_{p}\right) t_{j}}\right]
$$

onde o elemento pai $(p)$, com meia-vida $T_{1 / 2}(p)$ e constante de decaimento $\lambda_{p}$, decai a uma fração $f$ para o elemento filho $(d)$, que possui meia-vida $T_{1 / 2}(d)$ e constante de decaimento $\lambda_{d}$. Na equação $4.3, N_{p}$ e $N_{d}$ representam o número de átomos do radionuclídeo pai e do radionuclídeo filho, respectivamente, e as constantes de decaimento $(\lambda)$ são calculadas em função das meias-vidas $\left(T_{1 / 2}\right)$ de acordo com a equação 1.2 .

O Tecnécio-99m, elemento bastante utilizado na medicina nuclear como ferramenta para o diagnóstico de várias doenças ou disfunções de órgãos e sistemas que compõem o corpo humano (Marques et al., 2001), é gerado a partir do Molibdênio-99 cuja cadeia de decaimento apresentada na Figura 1.1 configura um exemplo de problema rígido com taxa de rigidez calculada pela equação 2.14 valendo aproximadamente $0,28 \times 10^{8}$. Para esta cadeia, consideramos a hora como unidade padrão. Uma associação entre as meias-vidas dos elementos da cadeia e suas constantes de decaimento é apresentada na Tabela 4.4.

\begin{tabular}{lcc}
\hline Elemento & Meia-Vida $T_{(1 / 2)}^{i}$ & Taxa de Decaimento $\lambda_{i}\left(\mathrm{em} \mathrm{hora}^{-1}\right)$ \\
\hline${ }^{99} \mathrm{Mo}$ & 66,02 horas & $0,104 \mathrm{E}-01$ \\
${ }^{99 m} \mathrm{Tc}$ & 6,02 horas & $0,115 \mathrm{E}+00$ \\
${ }^{99} \mathrm{Tc}$ & 213000 anos & $0,371 \mathrm{E}-09$ \\
\hline
\end{tabular}

Tabela 4.4: Meias-vidas e constantes de decaimento da série de decaimento do ${ }^{99}$ Mo (Kocher, 1981).

Assumindo que no instante de tempo $t_{j}$ existe 1 unidade do elemento de interesse da cadeia, o Tecnécio-99m, utilizamos a equação 4.3 para o cálculo da quantidade de cada isótopo radioativo presente na cadeia no instante $t_{j}$. A Tabela 4.5 mostra o inventário dos elementos para diferentes valores de $t_{j}$.

A partir dos valores apresentados na Tabela 4.5 é possível calcularmos numericamente, 


\begin{tabular}{lccc}
\hline$t_{j}$ (horas) & Molibdênio-99 & Tecnécio-99m & Tecnécio-99 \\
\hline 1 & $0,113 \mathrm{E}+03$ & $0,100 \mathrm{E}+01$ & $0,266 \mathrm{E}+00$ \\
10 & $0,174 \mathrm{E}+02$ & $0,100 \mathrm{E}+01$ & $0,239 \mathrm{E}+01$ \\
66 & $0,113 \mathrm{E}+02$ & $0,100 \mathrm{E}+01$ & $0,199 \mathrm{E}+04$ \\
100 & $0,113 \mathrm{E}+02$ & $0,100 \mathrm{E}+01$ & $0,100 \mathrm{E}+06$ \\
\hline
\end{tabular}

Tabela 4.5: Inventário dos elementos da cadeia do Molibdênio-99 para diferentes valores de $t_{j}$.

por meio dos métodos implementados, a quantidade de cada elemento da série para qualquer tempo $t \in \mathbb{R}$ com um erro inferior a uma precisão pré-fixada. A Figura 4.16 mostra o inventário da cadeia de decaimento do Molibdênio-99 em função do tempo para o caso em que $t_{j}=10$ horas (h) e a precisão exigida é $10^{-4}$. Para este caso, a Tabela 4.6 apresenta as soluções calculadas pelos métodos Rosenbrock e Radau II para cada um dos elementos da cadeia para $t=0 \mathrm{~h}, t=10 \mathrm{~h}$ e $t=130 \mathrm{~h}$. A partir de $t_{j}=10$ fomos capazes de reconstruir o inventário de cada elemento desde $t=0$ e estimar a quantidade de cada um deles para um tempo futuro. Para este problema, tanto o método Radau II como o Rosenbrock apresentaram bom desempenho executando apenas algumas dezenas de iterações de cada método.

\begin{tabular}{lll}
\hline$t$ (horas) & Rosenbrock & Radau II \\
\hline \multirow{4}{*}{$t=0$} & ${ }^{99}$ Mo: $0,1938 \mathrm{E}+02$ & ${ }^{99} \mathrm{Mo}: 0,1938 \mathrm{E}+02$ \\
& ${ }^{99 m}$ Tc: $0,0000 \mathrm{E}+00$ & ${ }^{99 m}$ Tc: $0,0000 \mathrm{E}+00$ \\
& ${ }^{99}$ Tc: $0,1462 \mathrm{E}+01$ & ${ }^{99} \mathrm{Tc}: 0,1462 \mathrm{E}+01$ \\
\hline \multirow{3}{*}{$t=10$} & ${ }^{99}$ Mo: $0,1745 \mathrm{E}+02$ & ${ }^{99} \mathrm{Mo}: 0,1745 \mathrm{E}+02$ \\
& ${ }^{99 m}$ Tc: $0,1000 \mathrm{E}+01$ & ${ }^{99 m}$ Tc: $0,1000 \mathrm{E}+01$ \\
& ${ }^{99}$ Tc: $0,2394 \mathrm{E}+01$ & ${ }^{99}$ Tc: $0,2394 \mathrm{E}+01$ \\
\hline \multirow{3}{*}{$t=130$} & ${ }^{99}$ Mo: $0,4952 \mathrm{E}+01$ & ${ }^{99} \mathrm{Mo}: 0,4952 \mathrm{E}+01$ \\
& ${ }^{99 m}$ Tc: $0,4372 \mathrm{E}+00$ & ${ }^{99 m}$ Tc: $0,4372 \mathrm{E}+00$ \\
& ${ }^{99}$ Tc: $0,1546 \mathrm{E}+02$ & ${ }^{99} \mathrm{Tc}: 0,1546 \mathrm{E}+02$
\end{tabular}

Tabela 4.6: Inventário da cadeia de decaimento do Molibdênio-99 para o caso em que $t_{j}=10 \mathrm{~h}$. 


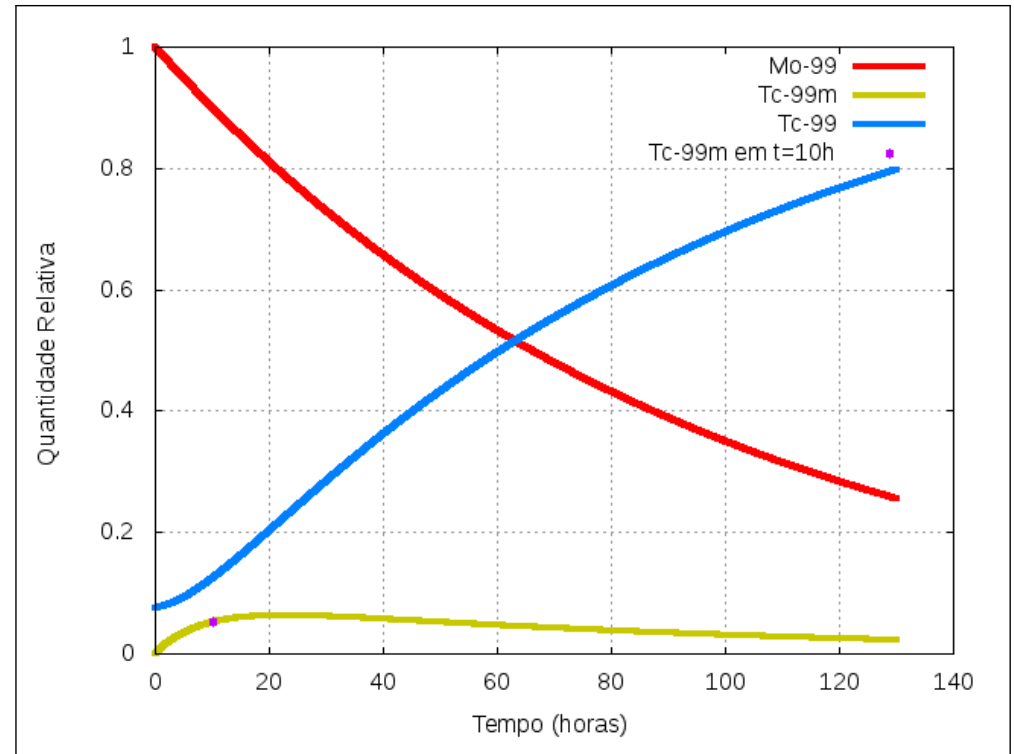

Figura 4.16: Inventário da cadeia de decaimento do Molibdênio-99 para o caso em que $t_{j}=10 \mathrm{~h}$.

As Figuras 4.17 à 4.20 mostram em escala logarítmica as soluções de cada elemento para todos os casos da Tabela 4.5. Mais uma vez, os métodos implementados apresentaram resultados estáveis e precisos com um desempenho semelhante entre eles, tanto no que diz respeito ao número de iterações quanto ao tempo computacional, demorando poucos segundos para determinar a solução numérica.

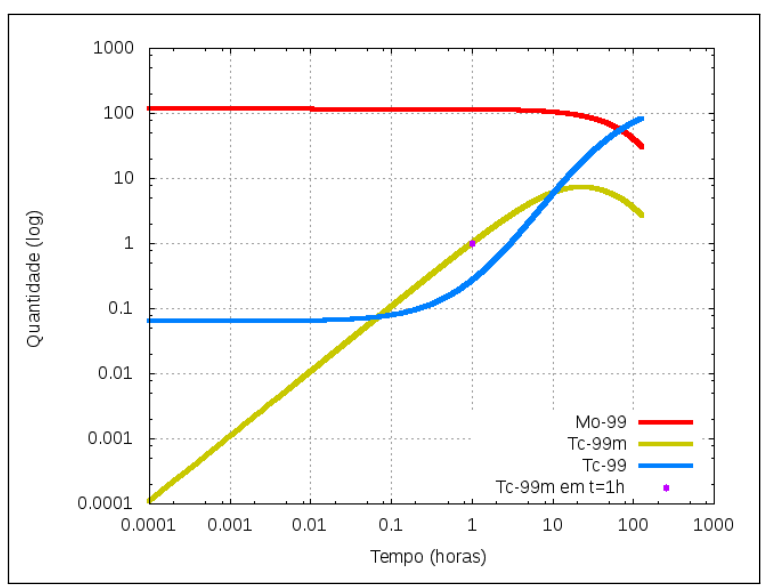

Figura 4.17: Cadeia do Molibdênio-99 para $t_{j}=1 h$.

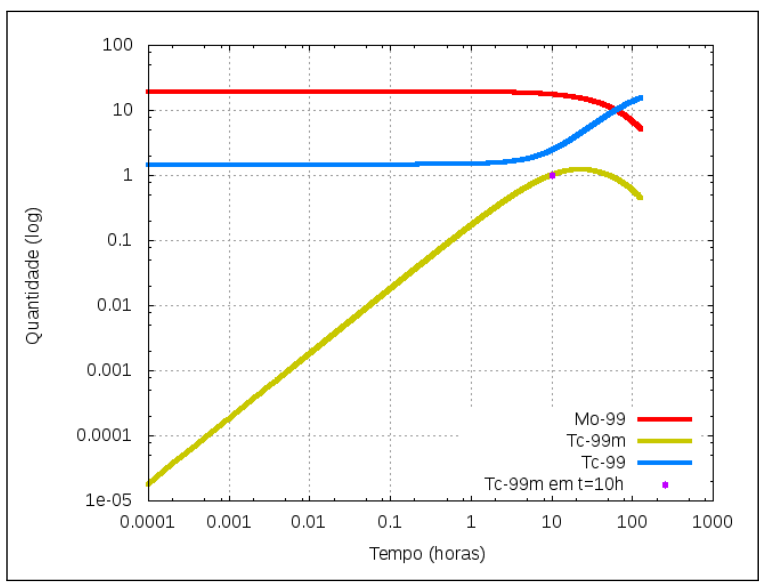

Figura 4.18: Cadeia do Molibdênio-99 para $t_{j}=10 h$. 


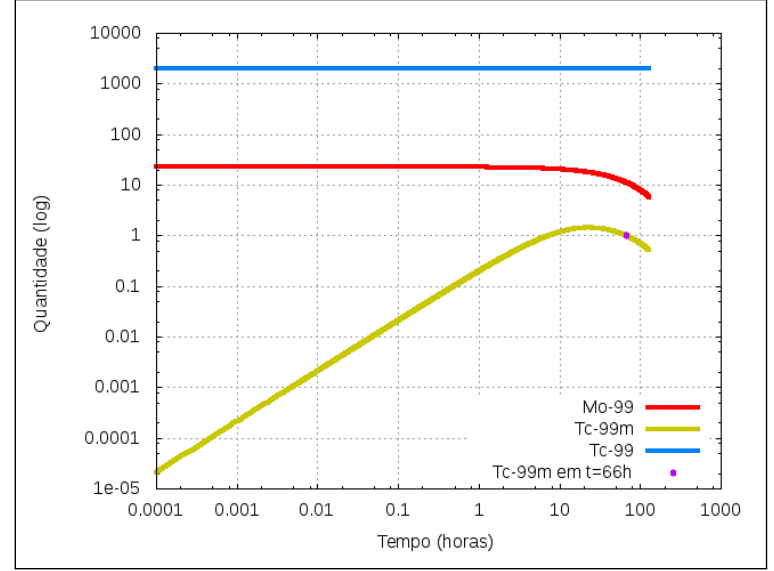

Figura 4.19: Cadeia do Molibdênio-99 para $t_{j}=66 h$.

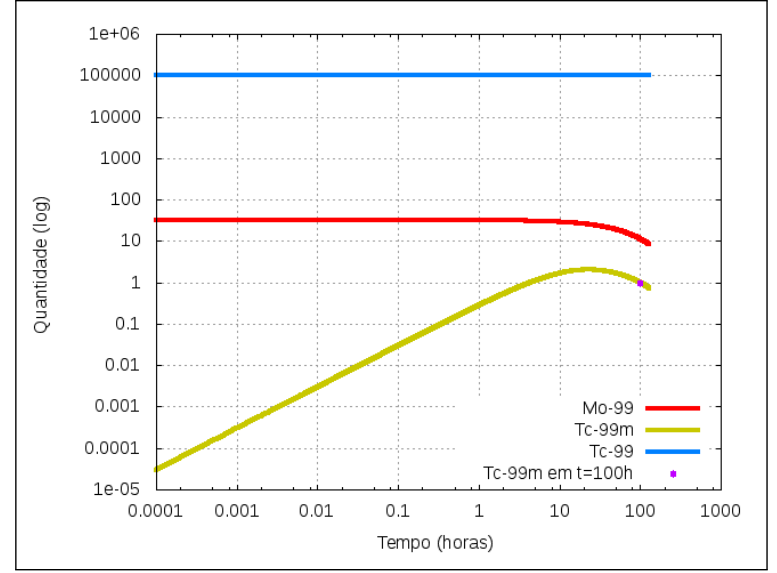

Figura 4.20: Cadeia do Molibdênio-99 para $t_{j}=100 h$

A abordagem utilizada para resolução deste problema pode ser empregada também na estimativa da quantidade inicial de Molibdênio-99 necessária para que seja possível a retirada periódica de uma determinada quantidade do elemento de interesse Tecnécio-99m.

Além disso, podemos utilizá-la também em outras situações que envolvem cadeias de decaimento radioativo. Vamos destacar como caso de uso uma situação de escape de elemento radioativo em ambiente monitorado periodicamente. A proteção radiológica dispõe de vários recursos para evitar que os indivíduos recebam doses excessivas ou desnecessárias de radiação, entre eles, as monitorações individuais e de área. Estas monitorações podem ser pontuais, periódicas ou contínuas, dependendo do ambiente, dos indivíduos e de suas atividades. Suponha que em determinado ambiente monitorado a cada período de tempo $P$, detectou-se a existência em excesso de certo elemento radioativo. Sabendo que na monitoração imediatamente anterior o ambiente não apresentava qualquer irregularidade, o objetivo é identificar a quantidade de elemento que vazou e o instante de tempo que isto ocorreu. Utilizando a mesma abordagem empregada no problema do Molibdênio-99 apresentado anteriormente, somos capazes de voltar no tempo e inferir uma região que apresenta a quantidade inicial de escape do elemento em função do possível instante de tempo que o acidente aconteceu. A Figura 4.21 mostra um esboço das etapas de monitoração e investigação do caso supra citado. 


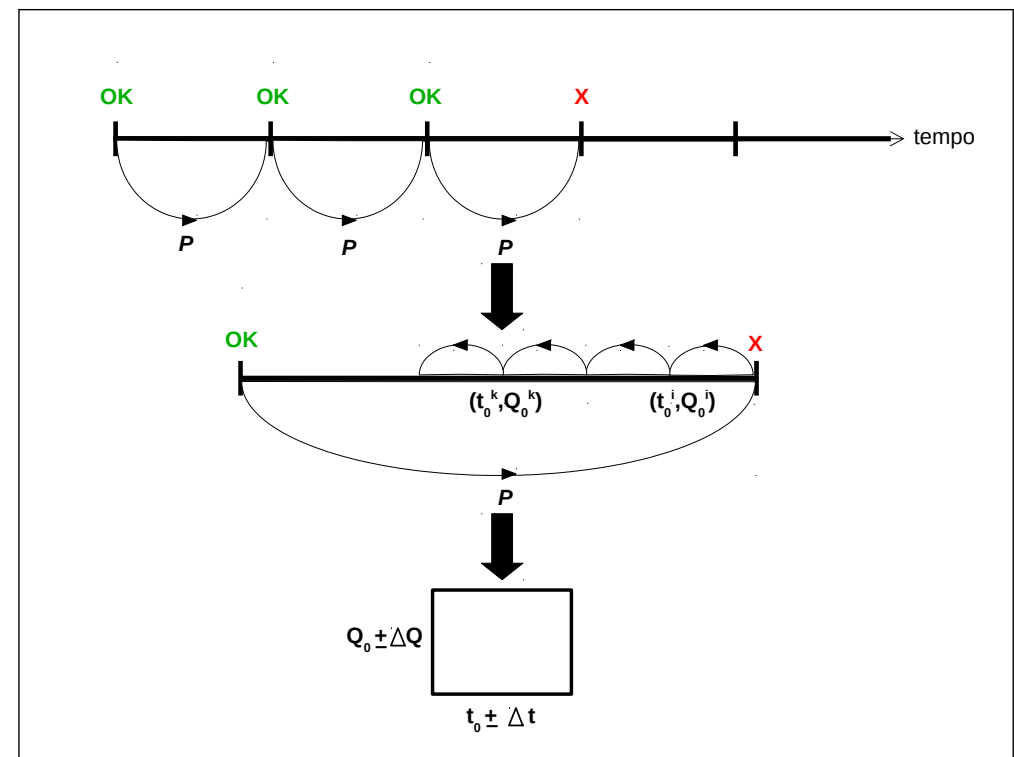

Figura 4.21: Abordagem em situação de vazamento/contaminação radioativa.

Esta aplicação destaca-se por ser uma importante demanda da área de proteção radiológica. 


\section{Capítulo 5}

\section{Conclusões}

Estudar técnicas numéricas adequadas à resolução de Equações Diferencias Ordinárias rígidas foi o objetivo principal deste trabalho. Não existe um conceito matemático único para rigidez, entretanto sabe-se que a rigidez é intrínseca ao problema e surge sempre que as componentes da solução variam com ordens de grandeza muito distintas. Problemas rígidos impõem dificuldades para convergência numérica quando resolvidos por métodos explícitos. Por outro lado, métodos implícitos absolutamente estáveis, que possuem região de estabilidade ilimitada, se comportam de maneira satisfatória e são os mais indicados para resolução deste tipo de problema. A estabilidade absoluta dos métodos implícitos possibilita o uso de estratégias de controle do tamanho do passo de integração sem comprometer a ordem de convergência e a estabilidade do método.

Os métodos numéricos implementados foram Radau II de 3 estágios e ordem 5 e Rosenbrock de 4 estágios e ordem 3(2), ambos de passo único, derivados dos métodos de RungeKutta e escolhidos por serem implícitos, de alta ordem de convergência e absolutamente estáveis (A-estáveis). Estes métodos utilizam estratégias de controle do passo de integração baseadas no erro cometido em cada iteração, estimado por meio de fórmulas embutidas de ordem inferior à ordem do método. O erro de convergência aceito é pré-determinado pelo usuário e o controle do passo é realizado de modo que a precisão seja mantida para todo o intervalo de avaliação do problema.

Problemas rígidos de decaimento radioativo envolvendo cadeias naturais e artificiais, com ou sem extração de elementos durante o processo de decaimento serviram como pano de fundo para a utilização dos métodos implementados. Um exemplo considerado foi o da cadeia de decaimento natual do Urânio-238, na qual as ordens de grandeza das constantes de decaimento dos elementos variam entre $10^{-12}$ e $10^{9}$, implicando na rigidez do problema. $\mathrm{O}$ resultado de destaque aqui é a possibilidade de reconstruirmos numericamente o inventário de uma cadeia de decaimento radioativo modelada por um sistema rígido de EDOs a partir de informações atuais, permitindo a obtenção de informações passadas e futuras dos elementos que compõem a cadeia.

Os métodos implementados mostraram-se eficientes e adequados para a classe de proble- 
mas estudada, produzindo soluções convergentes e estáveis dentro de uma precisão pré-fixada para todos os cenários propostos. Em um comparativo entre os métodos implementados, o método de Radau II obteve a mesma precisão que o método de Rosenbrock com um número menor de iterações em todos os casos considerados, porém esta diferença é pouco significativa, uma vez que ambos os métodos calcularam a solução com uma quantidade próxima de passos de integração e com o mesmo tempo de execução. Como os métodos possuem desempenho semelhante para os problemas considerados e a implementação do método de Radau II é mais trabalhosa do que a implementação do método de Rosenbrock, sugerimos o uso do Método de Rosenbrock para problemas dessa natureza, pois mostraram-se eficientes tanto para cadeias em equilíbrio como para problemas em dinâmica nos quais ocorre a retirada de determinadas quantidades de elementos da cadeia durante o processo de decaimento.

As técnicas numéricas aqui apresentadas corroboram os resultados produzidos na área de aplicação e podem ser utilizadas como plataforma inicial para abordagem de problemas futuros relacionados à produção ótima de radioisótopos, ao gerenciamento de rejeitos radioativos e a situações de emergência nuclear. 


\section{Apêndice A}

\section{Métodos de Euler Explícito e Implícito para Resolução de uma Equação Rígida}

Vamos considerar a equação (2.1) para compararmos o desempenho dos Métodos de Euler Explícito e Implícito e ratificarmos a afirmação de Curtiss e Hirschfelder (1952) que métodos explícitos apresentam maior dificuldade para resolução de equações rígidas.

Utilizando o Método dos Fatores Integrantes (Boyce e DiPrima, 2015) para o cáculo da solução geral da equação (2.1), temos:

$$
x(t)=C_{1} e^{5 t}+t^{2}+\frac{2 t}{5}+\frac{2}{25} .
$$

Vamos tomar como condição inicial $x(5)=50, t \in[5,6]$ e exigir uma precisão de $10^{-2}$ quando comparamos a solução aproximada com a solução analítica particular dada por:

$$
x(t)=\frac{573}{25} e^{5(t-5)}+t^{2}+\frac{2 t}{5}+\frac{2}{25} .
$$

Para se obter resultados com a precisão desejada é necessário que o método explícito utilize um passo de integração de tamanho $10^{-7}$, enquanto o método implícito atinge a mesma precisão com um passo de tamanho $10^{-4}$. Isto significa que para manter a precisão pré-definida é necessário que o método explícito calcule aproximadamente 9,9 milhões de iterações a mais do que o método implícito, conforme mostram as Tabelas A.1 e A.2. Observe que mesmo considerando uma pequena variação na variável $t$, a solução (A.2) da EDO cresce rapidamente, como mostra a Figura A.1. Esta rápida variação impõe dificuldades aos métodos para que a estabilidade seja mantida ao longo das iterações e a solução aproximada convirja para a solução analítica de acordo com a precisão desejada. 


\begin{tabular}{lcc}
\hline$t$ & Erro Absoluto & $\mathrm{N}^{\mathrm{o}}$ de Passos \\
\hline 5,2 & $3,8 \mathrm{E}-06$ & $2,0 \mathrm{E}+6$ \\
5,4 & $8,0 \mathrm{E}-05$ & $4,0 \mathrm{E}+6$ \\
5,6 & $8,3 \mathrm{E}-04$ & $6,0 \mathrm{E}+6$ \\
5,8 & $1,6 \mathrm{E}-03$ & $8,0 \mathrm{E}+6$ \\
6,0 & $4,6 \mathrm{E}-03$ & $1,0 \mathrm{E}+7$ \\
\hline
\end{tabular}

Tabela A.1: Desempenho do Método de Euler Explícito para a Equação 2.1.

\begin{tabular}{lcc}
\hline$t$ & Erro Absoluto & $\mathrm{N}^{\circ}$ de Passos \\
\hline 5,2 & $3,2 \mathrm{E}-05$ & $2,0 \mathrm{E}+3$ \\
5,4 & $2,0 \mathrm{E}-04$ & $4,0 \mathrm{E}+3$ \\
5,6 & $6,5 \mathrm{E}-04$ & $6,0 \mathrm{E}+3$ \\
5,8 & $3,1 \mathrm{E}-03$ & $8,0 \mathrm{E}+3$ \\
6,0 & $2,0 \mathrm{E}-03$ & $1,0 \mathrm{E}+4$ \\
\hline
\end{tabular}

Tabela A.2: Desempenho do Método de Euler Implícito para a Equação 2.1.

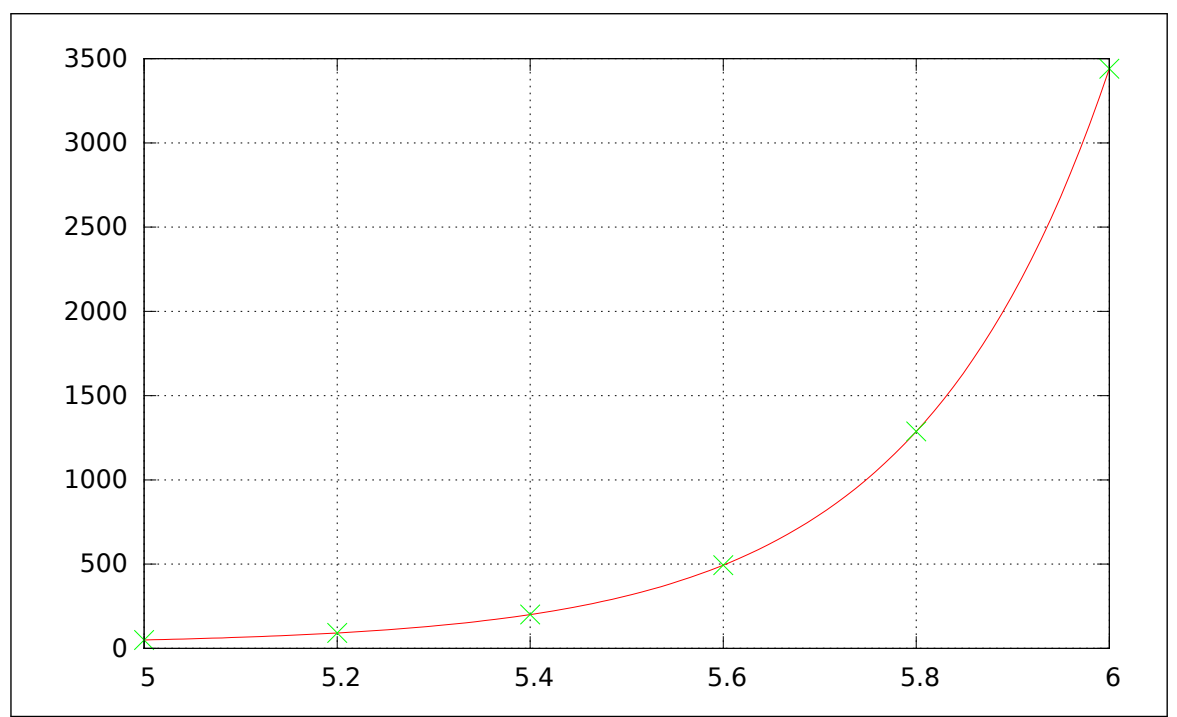

Figura A.1: Gráfico da Solução Analítica Particular (A.2). 


\section{Referências Bibliográficas}

Bateman(1910) H. Bateman. The solution of a system of differential equations occurring in the theory of radioactive transformations. Proc. Cambridge Philos. Soc., 15:423-427. Citado na pág. 14

Boyce e DiPrima(2015) William E. Boyce e Richard C. DiPrima. Equações Diferenciais Elementares e Problemas de Valores de Contorno. LTC, 10 ded edição. Citado na pág. 49

Brugnano et al.(2015) Luigi Brugnano, Felice Iavernaro e Cecilia Magherini. Efficient implementation of radau collocation methods. Applied Numerical Mathematics, 87:100113. Citado na pág. 20

Burden e Faires(2005) R. L. Burden e J. D. Faires. Numerical Analysis. Thomson Brooks/Cole. Citado na pág. 6

Butcher(1964a) J. C. Butcher. Implicit runge-kutta processes. Math. Comput., 18:50-64. Citado na pág. 22

Butcher(1964b) J. C. Butcher. Integration processes based on radau quadrature formulas. Math. Comput., 18:233-244. Citado na pág. 23, 24

Cash(2003) J. R. Cash. Efficient numerical methods for the solution of stiff initial-value problems and differential algebraic equations. Proc. R. Soc. Lond. A, 459:797-815. Citado na pág. 19

Cetnar(2006) J. Cetnar. General solution of bateman equations for nuclear transmutations. Ann. Nucl. Energy, 33:640-645. Citado na pág. 14

Claro(2011) Thiago Ribeiro Claro. Desenvolvimento de um código computacional de apoio ao cálculo de dose interna para radionuclídeos de interesse do ipen. Dissertação de Mestrado, Instituto de Pesquisas Energéticas e Nucleares - CNEN/SP, Brasil. Citado na pág. 21

Curtiss e Hirschfelder(1952) C. F. Curtiss e J. O. Hirschfelder. Integration of stiff equations. Proc. Natl. Acad. Sci., 38:235-243. Citado na pág. 7, 8, 11, 15, 49

da Silva et al.(2009) Láuris Lucia da Silva, Claudio Luis Donnici, José Danilo Ayala, Cíntia Helena de Freitas, Rubens Martins Moreira e Amenônia Maria Ferreira Pinto. Traçadores: O uso de agentes químicos para estudos hidrológicos, ambientais, petroquímicos e biológicos. Quim. Nova, 32(6):1576-1585. Citado na pág. 2

Dahlquist(1963) Germund G. Dahlquist. A special stability problem for linear multistep methods. BIT Numerical Mathematics, 3(1):27-43. Citado na pág. 19 
de Araújo et al.(2008) Elaine Bortoleti de Araújo, Tatiana Lavinas, Maria Tereza Colturato e Jair Mengatti. Garantia da qualidade aplicada à produção de radiofármacos. Revista Brasileira de Ciências Farmacêuticas, 44(1):1-12. Citado na pág. 2

de Carvalho(2006) Ricardo Pinto de Carvalho. Desenvolvimento de um simulador de treinamento para operadores do reator de pesquisa iea-r1. Dissertação de Mestrado, Instituto de Pesquisas Energéticas e Nucleares - CNEN/SP, Brasil. Citado na pág. 21

Deuflhard e Bornemann(2002) Peter Deuflhard e Folkmar Bornemann. Scientific Computing with Ordinary Differential Equations. Springer. Citado na pág. 1, 7

Hairer e Wanner(1996) Ernest Hairer e Gerhard Wanner. Solving Ordinary Differential Equation II: Stiff and Differential-Algebraic Problems. Springer-Verlag, $2^{a}$ edição. Citado na pág. $6,11,23,24,27,28,29,30,31$

Hairer et al.(1987) Ernest Hairer, Syvert Paul Norset e Gerhard Wanner. Solving Ordinary Differential Equations I: Nonstiff Problems. Springer-Verlag, $1^{\text {a }}$ edição. Citado na pág. 15, 22

Hairer e Wanner(1999) Ernst Hairer e Gerhard Wanner. Stiff dfferential equations solved by radau methods. Journal of Computational and Applied Mathematics, 111:93-111. Citado na pág. 20

International Atomic Energy Agency(2003) International Atomic Energy Agency. Manual For Reactor Produced Radioisotopes. IAEA. Citado na pág. 2

International Atomic Energy Agency(2004) International Atomic Energy Agency. Radioisotope Handling Facilities and Automation of Radioisotope Production. IAEA. Citado na pág. 1

International Atomic Energy Agency(2009a) International Atomic Energy Agency. Cyclotron produced radionuclides: physical characteristics and production methods. IAEA. Citado na pág. 2

International Atomic Energy Agency(2009b) International Atomic Energy Agency. Policies and strategies for radioactive waste management. IAEA. Citado na pág. 3

Isotani et al.(2012) Sadao Isotani, Walter Maigon Pontuschka e Seiji Isotani. An algorithm to optimize the calculation of the fourth order runge-kutta method applied to the numerical integration of kinetics coupled differential equations. Applied Mathematics, 3 (11):1583-1592. Citado na pág. 21

Kaps e Wanner(1981) P. Kaps e G. Wanner. A study of rosenbrock-type methods of high order. Numer. Math., 38:279-298. Citado na pág. 31

Kaps et al.(1985) P. Kaps, S. W. H. Poon e T. D. Bui. Rosenbrock methods for stiff odes: A comparison of richardson extrapolation and embedding technique. Computing, 34(1): 17-40. Citado na pág. 31

Kaps e Rentrop(1979) Peter Kaps e Peter Rentrop. Generalized runge-kutta methods of order four with stepsize control for stiff ordinary differential equations. Numerische Mathematik, 33(1):55-68. Citado na pág. 20

Kocher(1981) D. C. Kocher. Radioactive Decay Data Tables: A handbook of decay data for application to radiation dosimetry and radiological assessment. DOE/TIC-I 1026. Citado na pág. ix, xi, 3, 4, 5, 36, 42 
Lambert(1991) J. D. Lambert. Numerical Methods for Ordinary Differential Systems: the Initial Value Problem. John Wiley \& Sons. Citado na pág. 1, 6, 11, 16, 22

Liao(2015) Wenyuan Liao. A strongly a-stable time integration method for solving the nonlinear reaction-diffusion equation. Abstract and Applied Analysis, 2015. doi: 10.1155/ 2015/539652. Citado na pág. 20

Loch et al.(2013a) Guilherme Galina Loch, Joyce da Silva Bevilacqua e Orlando Rodrigues Jr. Desempenho dos métodos de runge-kutta 4-4 e rosenbrock em função da posição do lambda-crítico em sistemas rígidos. Em Anais do Congresso de Matemática Aplicada e Computacional CMAC Sudeste 2013, páginas 713-718. SBMAC. Citado na pág. 36

Loch et al.(2013b) Guilherme Galina Loch, Joyce da Silva Bevilacqua, Orlando Rodrigues Jr e Goro Hiromoto. Stiff systems associated with the radioisotopes production, November 2013b. Presented in Oral Session of BIOMAT 2013: International Symposium on Mathematical and Computational Biology, Fields Institute, Toronto, Ontario, Canada, 2013. Citado na pág. 36

Loch et al.(2013c) Guilherme Galina Loch, Joyce da Silva Bevilacqua, Orlando Rodrigues Jr e Goro Hiromoto. Análise de soluções numéricas para as equações de bateman. Em Anais do IX Latin American IRPA Regional Congress on Radiation Protection and Safety - IRPA 2013. SBPR. Trabalho apresentado no IRPA 2013, Rio de Janeiro - RJ, Brasil, 2013. Citado na pág. 20

Loch et al.(2015) Guilherme Galina Loch, Joyce da Silva Bevilacqua, Orlando Rodrigues Jr e Goro Hiromoto. Recuperação do inventário inicial em cadeias de decaimento radioativo. Em Proceeding Series of the Brazilian Society of Computational and Applied Mathematics, volume 3. SBMAC. doi: 10.5540/03.2015.003.01.0357. Trabalho apresentado no XXXV CNMAC, Natal - RN, Brasil, 2014. Citado na pág. 42

Luiz et al.(2011) L. C. Luiz, D. L. Brandão e R. T. Batista. Avaliação de um grupo de profissionais de saúde sobre os conceitos físicos e toxicológicos dos radiofármacos que utilizam os radioisótopos ${ }^{123} \mathrm{i}$ e ${ }^{131} \mathrm{i}$. Physicae, 10:13-19. Citado na pág. 2

Marques et al.(2001) Fabio Luiz Navarro Marques, Miriam Roseli Yoshie Okamoto e Carlos Alberto Buchpiguel. Alguns aspectos sobre geradores e radiofármacos de tecnécio-99m e seus controles de qualidade. Radiol Bras, 34(4):233-239. Citado na pág. 42

Miranker(1981) Willard L. Miranker. Numerical Methods for Stiff Equations and Singular Pertubation Problems. Reidel Publishing Company, $1^{\text {a }}$ edição. Citado na pág. 9, 10, 11, 15

Okuno e Yoshimura(2010) E. Okuno e E. Yoshimura. Física das Radiações. Oficina de Textos. Citado na pág. 1, 6

Pessanha et al.(2005) José E. O. Pessanha, Carlos Portugal e Alex A. Paz. Técnicas de solução de sistemas de equações diferencias e algébricas: Aplicação em sistemas de energia elétrica. Revista Controle \& Automação, 16(3):359-372. Citado na pág. 28

Pino e Giovedi(2005) E. S. Pino e C. Giovedi. Radiação ionizante e suas aplicações na indústria. Revista UNILUS Ensino e Pesquisa, 2(2):47-51. Citado na pág. 1, 2

Radau(1880) R. Radau. Étude sur les formules dapproximation qui servent à calculer la valeur numérique dune intégrale définie. Journal de Mathématiques Pures et Appliquées, 6:283-336. Citado na pág. 23 
Roma e Nós(2012) Alexandre Megiorin Roma e Rudimar Luiz Nós. Tratamento numérico de equações diferenciais map 5725. Notas de Aula, 2012. Citado na pág. 22

Rosenbrock(1963) H. H. Rosenbrock. Some general implicit processes for the numerical solution of differential equations. The Computer Journal, 5(4):329-330. Citado na pág. 23

Sandu et al.(1997) A. Sandu, J. G. Verwer, J. G. Blom, E. J. Spee, G. R. Carmichael e F.A. Potra. Benchmarking stiff ode solvers for atmospheric chemistry problems ii: Rosenbrock solvers. Atmospheric environment, 31(20):3459-3472. Citado na pág. 20, 30, 31, 32

Sasser(1992) John E. Sasser. History of ordinary differential equations the first hundred years. Em Proceedings of The Midwest Mathematics History Conferences, Miami University, Oxford, Ohio. Citado na pág. 7

Semenov(2011) Mihail Semenov. Analyzing the absolute stability region of implicit methods of solving odes. arXiv:1101.4434, 1:1-15. Citado na pág. 6

Shampine(1982) Lawrence F. Shampine. Implementation of rosenbrock methods. ACM Trans. Math. Softw., 8(2):93-113. Citado na pág. 31

Shampine e Gear(1979) Lawrence F. Shampine e Charles William Gear. A users view of solving stiff ordinary differential equations. SIAM review, 21(1):1-17. Citado na pág. 1

Stoer e Bulirsh(1996) J. Stoer e R. Bulirsh. Introduction to Numerical Analysis. SpringerVerlag. Citado na pág. 6, 22

Takahashi(2004) Sergio Yukio Takahashi. Estudo comparativo da relação custo benefício dos métodos de produção de mo-99: Fissão de u-235 e reação de captura neutrônica no mo99. Dissertação de Mestrado, Instituto de Pesquisas Energéticas e Nucleares - CNEN/SP, Brasil. Citado na pág. 3

Takai e Hagino(2015) Shizuka Takai e Kouichi Hagino. Nuclear transmutation of longlived nuclides with laser compton scattering: Quantitative analysis by theoretical approach. Em Ken Nakajima, editor, Distributed Systems, páginas 3-11. Springer. Citado na pág. 21

Tello(1979) Jorge Manuel Sotomayor Tello. Lições de Equações Diferenciais Ordinárias. IMPA - Instituto de Matemática Pura e Aplicada. Citado na pág. 13

Thomas e Barber(1994) G. F. Thomas e D. H. Barber. Stiffness in radioactive decay chains. Ann. Nucl. Energy, 21 (5):309-320. Citado na pág. 1

Willoughby(1996) Ralph A. Willoughby. Proceedings of the International Symposium on Stiff Differential Systems. Plenum Press. Citado na pág. 1

Wolfbrandt(1977) Arne Wolfbrandt. A study of Rosenbrock processes with respect to order conditions and stiff stability. Tese de Doutorado, Chalmers University of Technology, Gothenburg, Sweden. Citado na pág. 31

Zamboni et al.(2011) Mauro Zamboni, Edson Toscano Cunha e Rachele Zanchetti Grazziotin. Braquiterapia endobrônquica com alta taxa de dose no tratamento paliativo do câncer do pulmão. Pulmão $R J, 20(2): 42-47$. Citado na pág. 40 